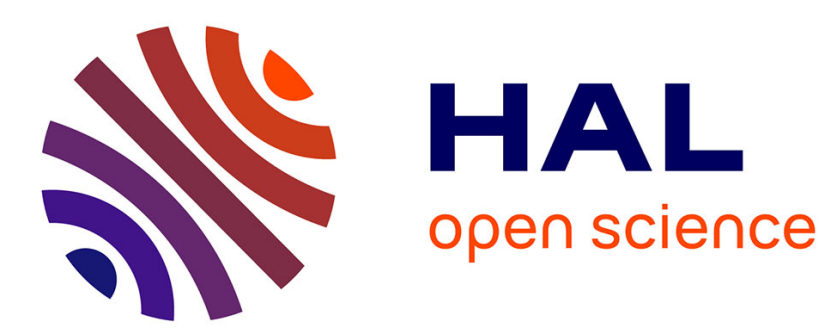

\title{
Electrotransfer of CpG free plasmids enhances gene expression in skin
}

S. Chabot, E. Bellard, J.P. Reynes, G. Tiraby, J. Teissié, Muriel Golzio

\section{To cite this version:}

S. Chabot, E. Bellard, J.P. Reynes, G. Tiraby, J. Teissié, et al.. Electrotransfer of CpG free plasmids enhances gene expression in skin. Bioelectrochemistry, 2019, 130, pp.107343. 10.1016/j.bioelechem.2019.107343 . hal-02390796

\section{HAL Id: hal-02390796 \\ https://hal.science/hal-02390796}

Submitted on 9 Dec 2020

HAL is a multi-disciplinary open access archive for the deposit and dissemination of scientific research documents, whether they are published or not. The documents may come from teaching and research institutions in France or abroad, or from public or private research centers.
L'archive ouverte pluridisciplinaire HAL, est destinée au dépôt et à la diffusion de documents scientifiques de niveau recherche, publiés ou non, émanant des établissements d'enseignement et de recherche français ou étrangers, des laboratoires publics ou privés. 


\section{Manuscript Details}

\section{Manuscript number}

Title

Article type
BIOELECHEM_2019_272

Electrotransfer of $\mathrm{CpG}$ free plasmids enhance gene expression in skin

Research Paper

\section{Abstract}

Skin is a very suitable target for gene therapy and DNA vaccination due to its accessibility, its surface, its ability to produce transgenes. Gene electrotransfer (GET) to the skin is under development for clinical applications for DNA vaccine or local treatment such as wound healing. Local treatments are effective if expression of the plasmid affects only the local environment (skin) by inducing an efficient concentration over a prolonged period. In this study, we evaluate the control of expression in the skin of a plasmid coding a fluorescent protein by its CpG (cytosinephosphate-guanine motif) content. Two fluorescent reporter genes are evaluated: dTomato and GFP. Expression is followed on a long term by in vivo fluorescence imaging. Our results show that GET mediated expression in the skin can be controlled by the $\mathrm{CpG}$ content of the plasmid. Expression on the long term (>120 days) can be obtained at a high level with $\mathrm{CpG}$-free constructs associated to a proper design of the electrodes where a field distribution mediating the gene electrotransfer is present deep in the skin.

Keywords

Manuscript category

Corresponding Author

Corresponding Author's Institution

Order of Authors

Suggested reviewers gene electrotransfer; electropermeabilization; electroporation; CpG free plasmid; skin; imaging

Electrochemistry of Biomedical Applications

justin Teissie

CNRS

Sophie Chabot, Bellard Elisabeth, Jean paul Reynes, Gerard Tiraby, justin Teissie, Muriel Golzio

SHULIN LI, Tristan Montier, emanuela signori, Gregor Sersa, Loree Heller

\section{Submission Files Included in this PDF}

File Name [File Type]

reponse 05-2019_EBjt $\mu$.docx [Cover Letter]

Highlights2.docx [Highlights]

draft-7.docx [Manuscript File]

Diapositive1.TIF [Figure]

Diapositive2.TIF [Figure]

Diapositive3.TIF [Figure]

Diapositive4.TIF [Figure]

Diapositive5.TIF [Figure]

Supplementary data.docx [Supporting File]

To view all the submission files, including those not included in the PDF, click on the manuscript title on your EVISE Homepage, then click 'Download zip file'. 


\section{Dear Professor Vadgama}

Please find attached the resubmission of the manuscript entitled "Electrotransfer of $\mathrm{CpG}$ free plasmids enhance gene expression in skin " by Chabot S, Bellard E, Jean-Paul Reynes, Gérard Tiraby, Justin Teissie, Muriel Golzio, we wish you to (re)consider for publication in Bioelectrochemistry as a research paper.

It was submitted as BIOELECHEM_2018_522 as a contribution to WC2 late in December 2018 but the decision was rejection. The comments of the reviewers were nevertheless positive and one of them asked for major revision or a resubmission.

We consider the reviewers' comments carefully and want to thank them for all the fruitful suggestions to improve our contribution mainly the need to carefully provide the statistical analysis.

The paper investigates the contribution of bacterial sequences (CpG loci) of the pDNA (affecting its size, its structure, its charge and its biological activity) on its GET mediated expression targeted to the skin by non-invasive electrodes. This point of a localized transfer to the skin and as a result expression was missed in the reviews.

Expression is observed and quantified by fluorescence imaging of the skin on living mice. The critical role of the "optical window" is now highlighted.

A point by point answers to the comments and suggestions of the reviewers of the previous version is as follows

\section{Reviewer 1}

This manuscript attempts to confirm, using electroporation, the observations of Yew et al 2002 that CpG motifs in plasmids reduce gene expression. However, some data are missing, some lack significance, and some statistical results are not included, limiting the value of this submission.

Yew's paper that was quoted in our contribution was "N.S. Yew, H. Zhao, M. Przybylska, I.H. Wu, J.D. Tousignant, R.K. Scheule, S.H. Cheng, CpG depleted plasmid DNA vectors with enhanced safety and long-term gene expression in vivo, Mol Ther, 5 (2002) 731-738." The result was that systemic delivery of cationic lipid-plasmid DNA ( $p D N A$ ) complexes induces an acute inflammatory response with adverse hematologic changes and liver damage. Our approach was on a targeted delivery (not systemic) by a physical method to the skin with a localized expression making it different from Yew's results. The role of CpG was first illustrated in a previous paper of the same group in Mol Ther. 2000 Mar;1(3):255-62. The conclusion was that the use of a less immunostimulatory pDNA vector or inhibitors of CpG immunostimulation can reduce significantly the toxicity associated with cationic lipid:pDNA complexes. No cationic lipids are used with GET.

Statistical analysis of the observations are now provided ( 2 Way ANOVA, post $t$-tests, one tailed). They support our conclusion of the effect with the tomato constructs.

\section{Introduction:}

Page 4: "DNA vaccines were effective due to the presence of specific immunostimulatory CG dinucleotides, known as CpG motifs [6, 7]." Two things should be added here

(1) probably some mention of TLR9 should be made in this paragraph. 
A reference to the Science paper of Matzinger is added in page 2.

(2) some discussion of the 6 nucleotide species specific consensus sequences should be made (Mouse specific: Yu et al 2003; Human specific: Bauer et al 2001).

This discussion is out of the topic of this paper as all the CpG dinucleotide were deleted in our constructs. Yu et al (Bioorg Med Chem. 2003 Feb 6;11(3):459-64) studied the immunostimulatory activity of synthetic CpG DNA and the requested proximity of specific nucleobases. In our paper, all the $\mathrm{CpG}$ dinucleotides were deleted in the constructs. There is no more CpGs even in the ORI type ori R6K. This ori is known to contain $\mathrm{CpG}$. Therefore, we produced an artificial origin with $\mathrm{CpG}$ free motives that were selected to give a functional combination. This information has been added in the Materials and method, plasmids section.

Page 4: "As a result, the expression was detected as localized in spots." This is a surprising statement; the precise reference where "spots" were observed should be specified.

In Gene Therapy volume 18, pages 258-265 (2011), the authors wrote: "Actual GFP transfection patterns appeared as distinct 'islands' around the contact point with each electrode". This supported by their fig. 2 shown bellow. In the legend, the authors wrote that transfection (i.e. expression) occurred at the contact point with the electrodes.

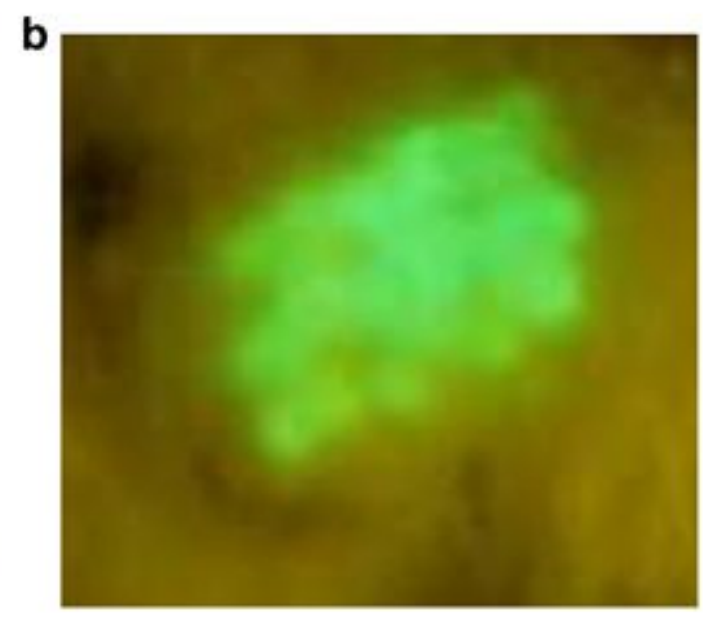

(b) Magnified ( $\times 3$ ) example of a single-treatment site showing the transfection occurring at the contact point with the electrodes.

In Molecular Therapy-Nucleic Acids (2016) 5, e356; doi:10.1038/mtna.2016.65, GET for DsRed reporter protein was obtained with a seven spring-loaded pins arranged in a hexagonal electrode array. Results and Methods are shown below as Fig.1 and 8 from the cited paper. As shown in fig.1 below, expression (fluorescence) is present as 4 spots with a diameter of less than $1 \mathrm{~mm}$ while the distance between each electrode was $3.5 \mathrm{~mm}$. 


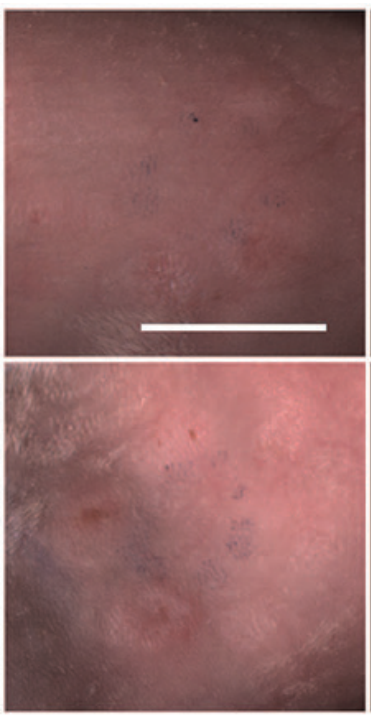

Vis
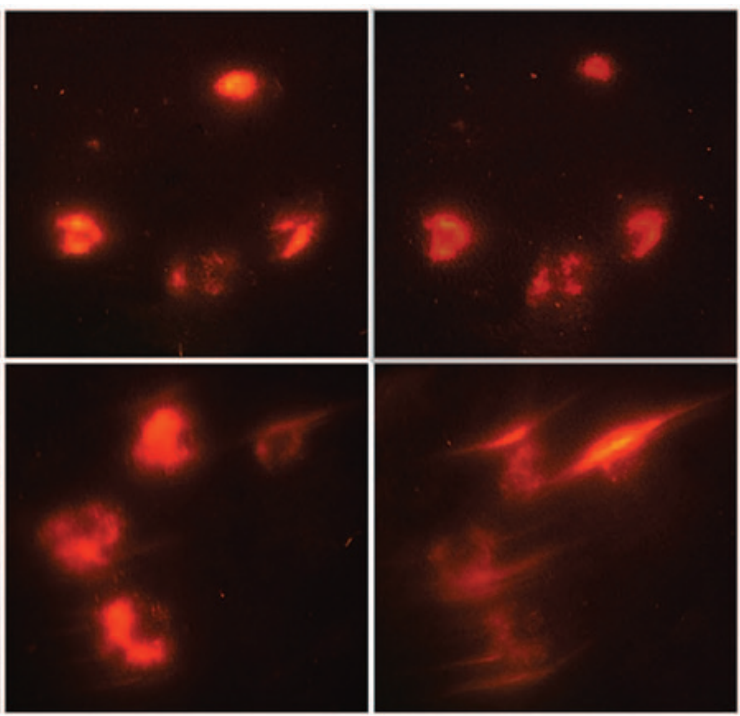

day 2

day 6

Fig 1: Fluorescence of DsRed protein following electrotransfer of the reporter plasmid coding for DsRed in mouse skin. (a) Representative images of the treated region of mouse skin showing the increased fluorescence signal due to intradermal injection of plasmid DNA followed by the application of highvoltage (HV)(upper row) or low-voltage (LV)(lower row) pulses. Images were acquired using the fluorescence stereomicroscope at the designated times. Scale bar: $5 \mathrm{~mm}$.
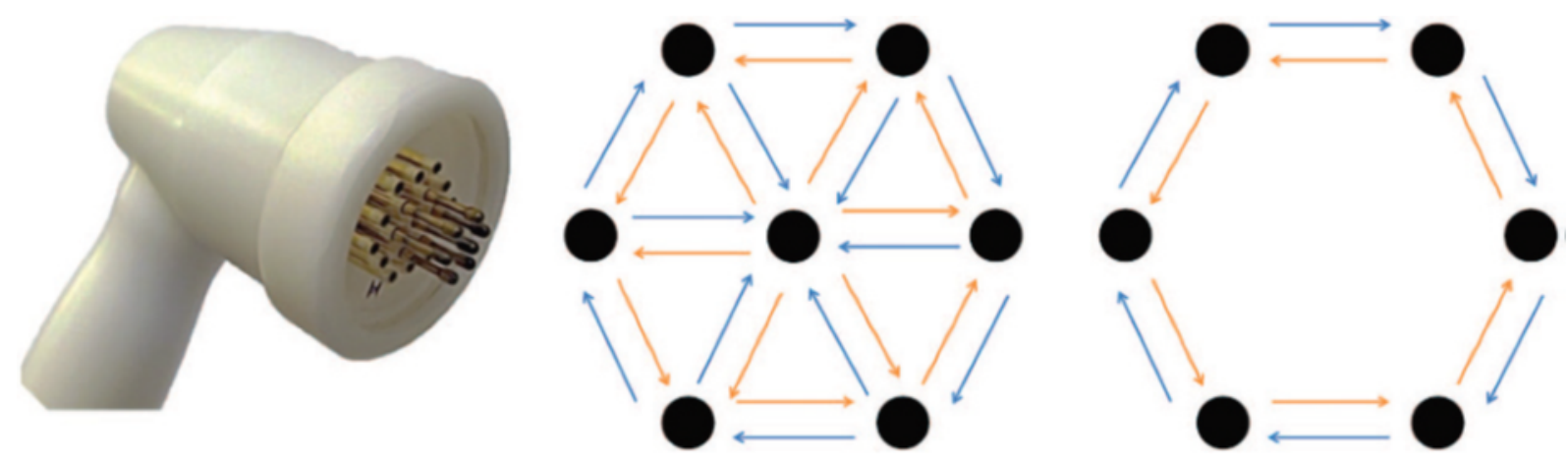

Fig 8: The electrode consists of seven spring-loaded pins arranged in a hexagonal mesh and spaced 3.5 mm apart.

Materials and Methods:

Page 5: Quantification of the mouse preferential 6-nucleotide consensus sequences within each plasmid should be included.

All CpG sequences were deleted in the constructs. See S1

Page 7: "Before carrying out statistical tests, we determined whether the data were normally distributed and evaluated their variance." How was normal distribution confirmed with a very small $n(n=3)$ ?

Sorry for the misunderstanding. We wrote in methods: "The mice were injected in two sites with 25 $\mu \mathrm{g}$ of plasmid in $25 \mu \mathrm{l} \mathrm{PBS}$ by intra-dermal (ID) route using a $300 \mu \mathrm{L}$ syringe with a $29 \mathrm{G}$ needle (Terumo, 
France). Injection lasted several seconds. Following ID injection of plasmid DNA, an electrical field pulse train was applied on each injection site with $10 \mathrm{~mm}$ long $\times 1 \mathrm{~mm}$ diameter contact wire electrodes". $\mathrm{n}$ $=2$ is the number of independent experiments. For dtTomato, 5 mice have been injected with CpGfree on one side and cpGrich on the other side, 4 mice with CpGfree on each side and 4 mice with CpGrich on each side $=$ total of 13 mice. For GFP, a total of 6 mice has been injected with cpGfree on one side and $\mathrm{cpGrich}$ on the other side. This is now corrected.

Results:

Figures legends 2, 3, 4, 5, 6: The pulse conditions are stated and diagrammed in Figure 1; since they do not change, it is not necessary to remind the reader repeatedly. More appropriately, Figure 1 (a variation of the figure in reference 30 ) should be deleted completely.

In reference 30, after optimization, 8 pulses lasting $20 \mathrm{~ms}$ at $120 \mathrm{~V}$ were applied. In the present study, due to the availability of a new pulse generator (Betatech B10), a more efficient pulse sequence was delivered for gene electrotransfer. Figure 1 is illustrative of the new pulse sequence.

Figures $2 \mathrm{~B}, 2 \mathrm{C}, 4 \mathrm{~B}, 4 \mathrm{C}$. The axes and labeling are not legible, even with magnification.

This is now corrected.

Are these representative samples?

Yes

Figure 3: Similar to Reference 30, CpG "Rich" tdTomato expression with identical pulse parameters and electrode lasts approximately day 18.

Pulse parameters were different in ref 30 as just explained. A low level expression (low fluorescence) was observed after D18 with the CpG rich plasmid.

Is the expression of "Free" tdTomato plasmid statistically significant after day 18? If not, time points above day 18 should be excluded.

As we were measuring the fluorescence emission, the expression was present and the levels at time points all over the experiments are significant. 2 way ANOVA demonstrated an effect of CpG. With post $t$-tests, we showed significant difference of expression from day 2 to 10 and from day 27 to day 130 at the exception of 2 days, 65 and 93 because of a high variability in data.

Is there a statistical difference between "Rich" and "Free" at any time point? Why are the data truncated at 110 days $(n=3)$ when the timeline in Figure $6 B(n=6)$ extends $>125$ days?

Sorry for truncated data. In Figure 3, we measured mean fluorescence on all 13 mice until 130 days. This is now corrected.

Figure 3B: It is important to include a similar graph for the GFP plasmid expression.

We agree and included a Figure 3B for GFP plasmid expression.

Figure 5: Can a statistical difference in relative expression be detected at any time point? Are the $t d$ Tomato results the same data in Figure 3 ? If statistical analysis were included with Figure $3 A$ and $3 \mathrm{~B}$, this repetitive figure should be deleted. 
We agree, by adding the graph for GFP in Figure 3, the previous figure 5 can be deleted. We removed it in the text. Statistical analysis is added on the 2 figures showing the statistical difference with the tdTomato.

Page 10: Since the differences are not significant, this statement should be deleted: "However, the enhancing effect of the deletion of the CpG sequence on the mean fluorescence intensity of the GFP protein was present but lower than the one of the tdTomato even though not significant (Fig.5)."

This was corrected. Fig5 is now deleted.

Figure 6: Depending on significance, Figure 3 may or may not show that expression of CpG-rich tdTomato plasmid lasts $\sim 20$ days while CpG-free plasmid expression lasts 110 days. Figure $6 \mathrm{~B}$ shows expression of _both_ versions can be detected $>125$ days. These figures disagree. What exactly is being shown in this figure? Statistics are needed.

Sorry Fig.3A is now including the results on D130 as for Fig.5 (previously Fig.6). Expression in animals in Fig. 5 is an all or not observation, not the quantitative results on Fig. $3 \mathrm{~A}$ (where the statistical analysis is present).

\section{Discussion:}

The first paragraph is a bit scrambled and should be reorganized to flow more logically. For example, these two concepts "The elongated stripes could be associated with the subdermal muscle fibers [2] [22]." and "Expression in muscle cells seemed present as long stripes of expression were observed on a long duration. A biophysical explanation was that the field distribution is heterogeneous [29] and a deeper penetration of field values supporting transfection was present in the volume in the middle of the electrode gap. The pulse settings with a long duration were reported to support expression in the deeper layers of the skin [2]." are separated by a discussion of keratinocytes.

The suggestion is now followed.

Also, could the electrode itself be responsible for the elongated shape?

The predicted field distribution is homogeneous in the plane parallel to the skin surface.

The differences with respect to the efficiency of in vivo detection between the fluors is vital to the manuscript and should be discussed. These publications and others may add insight into the issues with GFP vs. red fluorescent proteins (e.g. Weissleder and Ntziachristos, 2003, Deliolanis et al 2008, Shu et al 2009, many others).

We agree. In Gene Therapy volume 11, pages S85-S91 (2004), we reviewed the physical problems. Fluorescence imaging is controlled by the optical properties of tissues (reflexion, scattering, absorption). This results in the definition of an "optical window". Detection is far better with wavelengths larger than $600 \mathrm{~nm}$ than with shorter ones (when we worked in the visible range). This is further improved in the near infrared where very few fluorescent proteins are available.

The role of the "optical window" in the sensitivity of the detection was discussed in the methods part to explain our technological choice.

We added 2 references including Weissleder and Ntziachristos Nature Medicine volume 9, pages 123128 (2003) and our 2004 review. 
Highlight: "Higher and longer expression is obtained with CDG free constructs". Although, with possible statistical analysis, an argument can be made for higher expression, it appears that Figures 3 and 6 differ with respect to the length of expression, making this statement confusing.

This is corrected in this new form of the submission.

\section{-Reviewer 2}

Chabot et al. have submitted a manuscript reporting that CpG content is able to control the expression of two different reporter genes, dTomato and GFP, when delivered to mouse skin using in vivo electroporation. Both pattern and duration of expression were measured using non-invasive fluorescence microscopy. Based on the results, the author conclude that CpG free plasmids containing the dTomato reporter gene yielded a biphasic expression pattern that was higher than CpG rich plasmids both initially (Days 0-20) and longer term (Days 30-110) [Figure 3]. Based on these data, the authors conclude that reporter gene expression is controlled by CpG content of the plasmids.

While I appreciate the detailed information on the $H V$ and $M V$ pulse trains as well as the substantial efforts made to capture the reporter gene expression using microscopy (certainly no easy task), there are several major issues with the manuscript which would require a major revision and/or redo and resubmission of the manuscript.

Thanks for the positive evaluation. We followed your suggestions for this resubmission of the manuscript.

\section{1) Originality}

Other researchers have made similar observations about plasmid expression and CpG content, e.g., Suzuki et al. in 2018 (https://doi.org/10.1248/bpb.b18-00342) and Krinner et al. in 2015 (PMID: 26414116)

and this is a widely held view in the naked DNA field, so this is not a novel concept. The authors should be more clear why they believe these data to be novel.

Suzuki's study was on the control of expression localized in in the liver where the hydrodynamic injection was used leading to a different pathway for gene transfer. Krinner 's paper was dealing on cell systems observing GFP expression modulation. Our study is on another system, the skin, where GFP emission is out of the optical window. Transfer and expression in the skin is complex due to the multicellular organization. Inflammation is triggered that affect the tissue response and the level of protein expression.

2) Data Analysis It was unclear to this reviewer how many times this experiment was repeated. Figure legends mention " $n=3$ " or " $n=6$ " but was that number of mice or total number of sites/mouse?

Sorry for the misunderstanding In Methods, we wrote "The mice were injected in two sites with $25 \mu \mathrm{g}$ of plasmid in $25 \mu \mathrm{l} \mathrm{PBS}$ by intra-dermal (ID) route using a $300 \mu \mathrm{L}$ syringe with a $29 \mathrm{G}$ needle (Terumo, France). Injection lasted several seconds. Following ID injection of plasmid DNA, an electrical field pulse train was applied on each injection site with $10 \mathrm{~mm}$ long $x 1 \mathrm{~mm}$ diameter contact wire electrodes". $\mathrm{n}$ is the number of independent experiments, 2 for each plasmid. For dtTtomato, 5 mice have been injected with CpGfree on one side and cpGrich on the other side, 4 mice with CpGfree on each side and 4 mice with CpGrich on each side $=$ total of 13 mice. For GFP, a total of 6 mice has been injected with CpGfree on one side and CpGrich on the other side. 
Furthermore, while the Methods section mentioned Statistical Analysis, I did not see any $p$ values or notations of significant differences in the data nor in the figures. Please point out the significant differences between $\mathrm{CpG}$ rich and $\mathrm{CpG}$ free.

This is now corrected in the new fig 3.

3) Conclusions The authors conclude that "GET mediated expression in the skin is controlled by the CpG content of the transfected plasmid." While the authors certainly found a different pattern of expression as noted in Figure 3, a more mechanistic analysis in vivo is warranted.

Just demonstrating a change in the pattern of expression is not sufficient to convince me that it is solely CpG content and not, for example, differences in transfection due to the electroporation procedure or some other variable due to the administration. I realize this is less likely, nevertheless, without a more definitive mechanism demonstrated through controlled experimentation it cannot be ruled out.

We discussed the control by the plasmid size of the transfection by the electroporation procedure (CpG free constructs are shorter). All other variables due to the administration were the same in all experiments (electrical parameters, plasmid injection, care of the animals).

Concerning the reviewers for this present version, previous names are suggested as they did a careful work and one of them suggested only a major revision. Their major concern was the lack of statistical analysis that is now provided. The only change is the editor, that should be you, as this manuscript is not for the special issue that is closed now.

Shulin Li, The University of Texas MD Anderson Cancer Center, Houston, TX sli4@mdanderson.org

- $\quad$ Gregor Sersa, Institute of Oncology Ljubljana Department of Experimental Oncology, Ljubljana Slovenia gsersa@onko-i.si

- $\quad$ Loree C Heller, Frank Reidy Research Center for Bioelectrics, Old Dominion University, Norfolk, VA Iheller@odu.edu.

- $\quad$ Emanuella Signori, University Campus Bio-Medico of Rome, Italy, emanuela.signori@ift.cnr.it

- $\quad$ Tristan Montier, Unité INSERM 1078, Brest, France, tristan.montier@univ-brest.fr.

We hope that this resubmitted (revised) version will be considered as acceptable for publication in Bielectrochemistry

Yours

J Teissie 
Gene electrotransfer (GET) to the skin is obtained with contact electrodes

Expression is followed on a long term by in vivo fluorescence imaging

GET mediated expression in the skin is controlled by the $\mathrm{CpG}$ content of the dtomato plasmid Higher and longer expression is obtained with CpG free construct 


\section{Electrotransfer of CpG free plasmids enhance gene expression in skin}

Chabot $\mathrm{S}^{1,3}$, Bellard E ${ }^{1}$, Jean-Paul Reynes ${ }^{2}$, Gérard Tiraby ${ }^{2}$, Justin Teissie ${ }^{1}$, Muriel Golzio ${ }^{1}$.

1 Institut de Pharmacologie et de Biologie Structurale, Université de Toulouse, CNRS, UPS, BP 64182, 205 Route de Narbonne, F-31077, France

2 Invivogen Cayla SAS, 5 rue Jean Rodier, Zone industrielle de Montaudran, F-31400 Toulouse, France

3 present adress : Urosphere SAS, Canal Biotech II, 3, rue des Satellites, F-31400 Toulouse

Corresponding authors: Golzio M, golzio@ipbs.fr

Teissie J, Justin.teissie@ipbs.fr

EB and SC contribute equally

Keywords: gene electrotransfer, electropermeabilization, electroporation, CpG free plasmid, skin, imaging

Abstract :

Skin is a very suitable target for gene therapy and DNA vaccination due to its accessibility, its surface, its ability to produce transgenes. Gene electrotransfer (GET) to the skin is under development for clinical applications for DNA vaccine or local treatment such as wound healing. Local treatments are effective if expression of the plasmid affects only the local environment (skin) by inducing an efficient concentration over a prolonged period. In this study, we evaluate the control of expression in the skin of a plasmid coding a fluorescent protein by its $\mathrm{CpG}$ (cytosine-phosphate-guanine motif) content. Two fluorescent reporter genes are evaluated: dTomato and GFP. Expression is followed on a long term by in vivo fluorescence imaging. Our results show that GET mediated expression in the skin can be controlled by the $\mathrm{CpG}$ content of the plasmid. Expression on the long term ( $>120$ days) can be obtained at a high level with CpG-free constructs associated to a proper design of the electrodes where a field distribution mediating the gene electrotransfer is present deep in the skin. 


\section{Introduction}

Skin is a very suitable target for gene therapy due to its easy accessibility for experiments, the large surface that can be treated and evaluated by biochemical and physical approaches and its ability to produce transgenes. Gene transfer can bring a local expression of proteins. A systemic effect can be obtained if the newly locally produced protein is transferred to the blood stream. Gene transfection of the skin affects various cell types in the different skin layers. Expression in keratinocytes that form the stratum corneum, is short lived as those cells have a fast turnover [1]. Expression in fibroblasts, subdermal fat cells and the subdermal muscles (in the case of mice) will persist on a much longer period [2]. Gene transfer can be obtained by viral methods but they are known to present some risks. Nonviral methods are safer at several levels: manufacturing, plasmid manipulation and the lack of risk of insertional mutagenesis. The major problem with non-viral approaches is the low level of transfection and the need of biochemical and/or physical delivery methods.

Gene electrotransfer (GET) appears as a very promising approach as expression is present only where the plasmid is present (control by the injection procedure) and where the local field is effective (control by the cell size, the electrode system and the voltage that is delivered)[3]. Gene electrotransfer to the skin is under development for clinical applications for DNA vaccine or local treatment such as wound healing. Local treatments are effective if expression of the plasmid affects only the local environment (skin) by inducing an efficient concentration over a prolonged period (targeting to long lived skin cells). GET appears a promising method as option for treatment of local and systemic skin disorders.

Besides the physical parameters controlling electrotransfer (voltage, pulse duration, number of repetitive pulses, delay between pulses, electrodes) [2] [4], a critical control is brought by the plasmid construct. Specific expression in a given tissue was shown to be controlled by the promoter [5]. DNA vaccines were effective due to the presence of specific immunostimulatory CG dinucleotides, known as CpG motifs [6, 7]. They appeared to act through their recognition by TRL9 receptors [8]. Plasmids used as a DNA vaccine contained on average approximately $200 \mathrm{CpG}$ moieties $[9,10]$. The full nature of the immune and tissue responses to nucleic acids and electrotransfer to the skin has not been addressed. It was observed in muscles that the nature of the inflammatory infiltrate and the kinetics of gene expression were different along electrotransfer by conventional and CpG-free plasmids [11]. A CpG adjuvant effect was required for DNA vaccines, but was not needed and perhaps harmful for a local gene effect. It was suggested that vectors for somatic cell gene therapy should be designed to lack these $\mathrm{CpG}$ repeats [7]. A recent study using a chemical delivery method for gene transfer observed that this was indeed the case. A plasmid was designed to avoid inflammation and to provide sustained transgene expression in lungs. It was CpG-free and under control of the human elongation factor-1 alpha promoter, a CpG free promoter. Mice transfected with this construct exhibited a higher and more sustained transgene (Luciferase) expression than those treated with a $\mathrm{CpG}$ rich plasmid with a CMV promoter[12].

The CpG sequences depletion in plasmids and promotor constructs were shown in vitro to decrease the magnitude and the lifetime of gene expression in isolated cells [13, 14]. In vivo, inflammation of the tissue was more important when a CpG rich plasmid was used for transfection. As a result, the level of $\mathrm{CpG}$ in the construct was controlling the in vivo expression $[15,16]$.

Skin GET has been approached by different groups using different electrode set-ups, all designed to deliver a field effect targeted to the skin. The plasmid solution in phosphate buffer saline (PBS) was intradermaly (ID) injected and the field was delivered on the skin around the bleb due to the injection. The different electrode systems provided different field distributions in the tissue that resulted in expression of the transfected gene in different layers of the skin. Plate parallel electrodes or tweezer 
electrodes where the skin was pinched between the electrodes gave a homogeneous field effect in the skin and in the tissue under the skin [17, 18] [19]. Array of contact non-invasive microelectrodes were popular as they could be used with low voltage but were associated with an heterogeneous field distribution. As a result, the expression was detected as localized in spots [2, 20]. Depth of expression in the skin was dependent on the electrode design and on the pulse sequence [2, 21, 22]. Minimally invasive needles were associated as with non-invasive arrays to the low voltage that was delivered and to a patterned expression due to the heterogeneous field distribution. Due to their invasive character, they were associated with a deep localization of gene expression, as the field strength remained effective for transfection even in the subdermal layers [20, 23, 24] [25, 26]. Microneedle roller associated to a flexible interdigitated electroporation array brought similar effects as the field distribution was similar but was obtained by a different electrode design [27]. Hollow conductive microneedles were used for (1) needle-free intradermal injection and (2) electric pulse application in order to achieve electric field in the superficial layers of the skin sufficient for electroporation. The field distribution and the pattern of expression were therefore similar to the minimally invasive systems [28]. Parallel rows of short slightly invasive electrodes gave a similar local field distribution and a depth of expression in the skin similar to the minimally invasive electrodes but with a global geometry of expression that was different [4].

These studies were developed for the use of DNA vaccines in the skin as this organ was rich in numerous immune cells such as dendritic and Langerhans cells that could elicit appropriate immune responses [29]. The constructs were CpG rich to get a strong immune response [7] [6]. Some studies were dealing with wound healing but again $\mathrm{CpG}$ rich constructs were used [17].

Our group introduced a few years ago another concept of non-invasive electrodes allowing the electrotreatment of a large skin area [30]. These contact electrodes were observed to be highly safe and efficient for electroimmunization [31]. Optimized electric parameters for skin GET were designed where a train (4) of a short high voltage pulse followed by a long low voltage one was delivered at a 1 $\mathrm{Hz}$ frequency. In the present investigation, we evaluated the control of expression of a plasmid coding for fluorescent protein by its CpG content. Expression was followed on a long term (more than 100 days) by in vivo fluorescence imaging.

\section{Materials and methods}

Mice: Female C57BI/6 mice, 6-9 weeks old were obtained from Janvier Labs (Le Genest St. Isle, Saint Berthevin, France). Animal studies were conducted in accordance with the principles and procedures outlined by the European convention for the protection of vertebrate animals used for experimentation. All experiments were approved by the local ethics committee $\left(n^{\circ} 20111028 / 151\right)$.

Plasmids: All plasmids were provided by Invivogen (Toulouse, France) (suppl data). Plasmids were kept in PBS at a concentration of $1 \mu \mathrm{g} / \mu \mathrm{L}$ and stored at $-20^{\circ} \mathrm{C}$. The CpG-free- and CpG-rich-tdTomato plasmids encoded the red fluorescent protein tdTomato. The CpG-free- and CpG-rich-GFP plasmids encoded the green fluorescent protein (GFP). All the CpG dinucleotides were deleted in the CpG-free constructs. There is no more CpGs even in the ORI type ori R6K.

Intra-dermal DNA injection and electric pulses delivery: Hair on the back was removed with a hair removal lotion (Veet, France) 2 days before each electro-transfection. Animals were kept under isoflurane/air anesthesia during the whole procedure. The mice were injected in two sites with $25 \mu \mathrm{g}$ of plasmid in $25 \mu \mathrm{l}$ PBS by intra-dermal (ID) route using a $300 \mu \mathrm{L}$ syringe with a $29 \mathrm{G}$ needle (Terumo, France). Injection lasted several seconds. Following ID injection of plasmid DNA, an electrical field pulse 
train was applied on each injection site with $10 \mathrm{~mm}$ long $x 1 \mathrm{~mm}$ diameter contact wire electrodes. The distance between the electrodes was $4 \mathrm{~mm}$. Conducting paste (Comepa, St Denis, France) was used to ensure good electrical contact between the electrodes and the skin surface. Non-invasive wire contact electrodes were designed to focus the field in the tissue layer close under the skin between the wires [30]. Treated skin surface was $0.5 \mathrm{~cm}^{2} .4$ trains of square wave (unipolar) pulses presented in figure 1 were delivered thanks to the $\beta$-tech pulse generator ELECTRO cell B10 (Betatech, St Orens, France). Pulses in the train were applied at the frequency of $1 \mathrm{~Hz}$ [32].

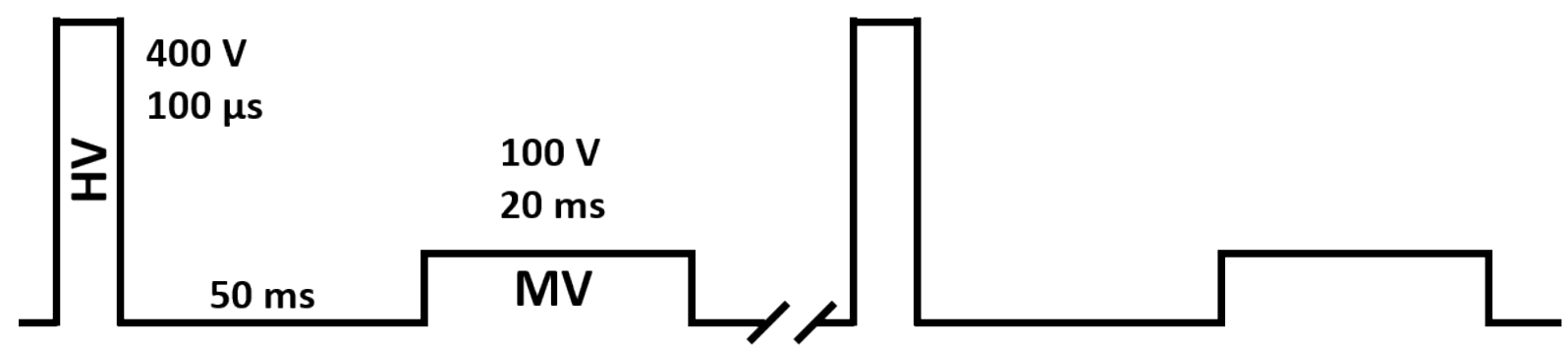

Fig. 1 High Voltage (HV) consists in $100 \mu$ square waved pulses of $400 \mathrm{~V}$ and Medium Voltage (MV) were $20 \mathrm{~ms}$ square waved pulses of $100 \mathrm{~V}$. The intermediate time delay was $50 \mathrm{~ms}$. The frequency was $1 \mathrm{~Hz}$.

The proper delivery of the pulses from the pulse generator was monitored on-line on the touch screen. A current-follower (Chauvin Arnoux, Paris, France) connected to a digitizer (Picoscope, St Neots, UK) was used to register the delivered current profiles. Voltage and current pulses were then stored on a USB key and are available on request.

In vivo fluorescence optical imaging of reporter gene, data acquisitions and processing: Visualization of fluorescent proteins expression was followed in vivo over several weeks after gene electrotransfer. Animals were kept under isoflurane anesthesia during the observation. A Macrofluo microscope (Leica, Wetzlar, Germany) was equipped with a cooled CCD camera (Roper Coolsnap HQ, Photometrics, Tucson, AZ (no binning)) using the 0.57 magnification (exposure time $1 \mathrm{~s} ; 100$ pixels are $1.5 \mathrm{~mm}$ ). Color imaging was obtained by use of CRI Micro*Color 2 Liquid Crystal Technology (Cambridge Research Instrumentation, Woburn, MA, USA). The fluorescence excitation was obtained with an EL6000 light source (Leica, Wetzlar, Germany) and either the $L 5(\lambda$ ex $=480 / 40 \mathrm{~nm}, \lambda \mathrm{em}=527 / 30 \mathrm{~nm}$ ) or the ET $\mathrm{mCH} / \mathrm{TR}$ ( $\lambda$ ex $=560 / 40 \mathrm{~nm}, \lambda \mathrm{em}=630 / 75 \mathrm{~nm}$ ) filter sets (Chroma technology, Rockingham, USA) for GFP and tdTomato observation, respectively. This procedure allowed analysis of vector expression on the same animal during several weeks. tdTomato plasmid coded for a protein with an emission in the red (wavelength longer than $630 \mathrm{~nm}$ ). Compared with GFP, this expression was more easily detected in the skin as its spectral range was in skin optical window, where light scattering and absorption were limited and did not alter the detection of the emission. Thus, it was used for most experiments. For images acquisition and quantification, the MetaVue5.2 software (Universal, Downingtown, PA, USA) and the Image J software (https://imagej.nih.gov/ij/) were used. Images were processed for contrast and brightness. High-resolution images of $1392 \times 1040$ pixels were captured directly on a Dell PC.

The analysis was obtained by selecting a ROI (region of interest) covering the region of emission with a large margin. The same ROI was kept when the same animal was observed during the duration of the monitoring (up to more than 100 days). The mean fluorescence was associated with the signal detected in the ROI. A similar ROI on the skin not transfected was used as an internal control. 
Statistical analyses: Quantitative data (presented as means \pm s.e.m.) were analyzed with Prism 4 software (GraphPad, San Diego, CA). Before carrying out statistical tests, we determined whether the data were normally distributed and evaluated their variance. We then carried out appropriate test as indicated. For in vivo time-course experiments, we used two-way ANOVA analysis. We reported the actual $P$-value for each test. $P<0.05$ was considered statistically significant.

\section{Results}

\section{Time course expression of the CpG-free-tdTomato plasmid in the skin after GET}

The fluorescence emission of the GET treated skin was monitored by in vivo imaging on a long period following the pulse delivery (Fig.2). The mean intensity was extracted from the successive images during the post GET treatment. Quantitative expression was detected by in vivo imaging analysis as shown on Fig.2. Emission is already increased on day 1 (Fig.3A). An increase in emission is present and levelled off on day 8 as just shown from the surface plot for the maximum emission. The area where fluorescence was observed was elongated reflecting the field distribution in the skin associated with the $1 \mathrm{~cm}$ long contact electrodes. The emission then decreased up to day 20 and this was followed by a slow increase giving a plateau over more than 100 days

Surface plot analysis of the skin imaging on days 4, 8 and 18 showed that the maximum emission already high on day 4 further increased on day 8 but slightly decreased on day 18 (Fig.2). Emission was not homogeneous and parallel stripes of higher emission were present. They were detected all along the experiments. Line plots of the emission were obtained along a direction perpendicular to these stripes. The width of the area where emission was above the background level (about 150) was of the same order of magnitude at day 4 and 8 but strongly decreased at day 18 (line plot width was reduced by $50 \%$ ).

A

D4

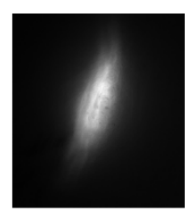

B

D8

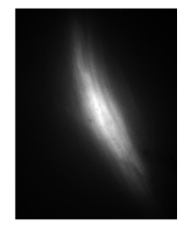

C

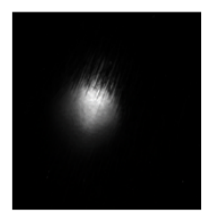

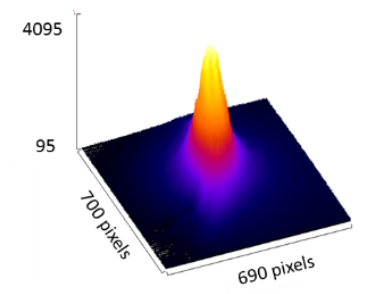

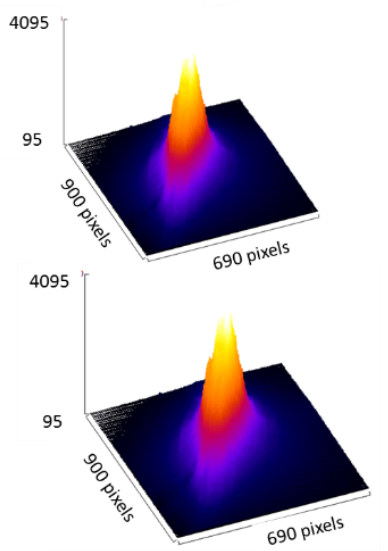

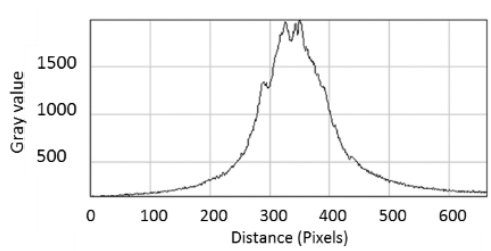
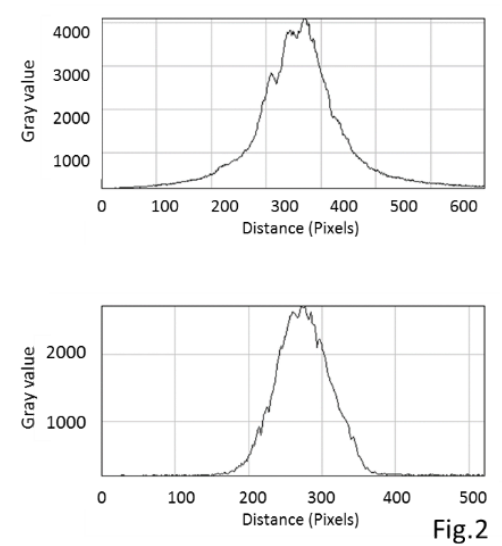
Fig. 2 Image analysis of the dTomato expression along the early part of the experiment

$25 \mu \mathrm{g}$ of CpG-free plasmid DNA coding the fluorescent protein tdTomato were intradermally injected in the back of anesthetized C57BI/6 mice and the electrotransfer was performed with contact electrodes using the HV-MV parameters (4 trains : $100 \mu \mathrm{s}, 400 \mathrm{~V}+20 \mathrm{~ms}, 100 \mathrm{~V}$ ). tdTomato expression was followed over time by non-invasive fluorescence microscopy. 100 pixels are $1.5 \mathrm{~mm}$.

A D4 Fluorescence image (700x750 pixels), surface plot, line plot B D8 Fluorescence image (700x900 pixels), surface plot, line plot

C D18 Fluorescence image (500x500 pixels), surface plot, line plot

Muscle contractions were present during the pulse train delivery. No damage to the skin in the pulsed area was observed. No critical symptom was observed after GET.

\section{Effect of the CpG content in tdTomato plasmid constructs}

Next, we compared the level of expression obtained between CpG-rich and CpG-free constructs (Fig 3A). tdTomato high expression was much longer time lived (more than 100 days) when using CpG-free construct compared to the expression obtained with CpG-rich constructs. A biphasic time course of fluorescence was observed composed of a high burst of expression with a peak at day 8 . The use of CpG-free plasmids provided a fluorescence intensity more than 5 fold higher at the peak of expression (Day 8). This peak was followed by a drop of expression and then by a slow increase giving a plateau over more than 100 days. The use of $\mathrm{CpG}$-free plasmids provided a fluorescence intensity more than 10 fold higher on the long term (30 days after electrotransfer) compared to CpG-rich plasmids. The biphasic time course of fluorescence was not observed with the CpG-rich construct. We observed a high burst of expression with a peak at day 8 followed by a drop of expression but not the second increase after day 20. Expression remained detectable but at a level 10 times lower than with the CpGfree constructs. 

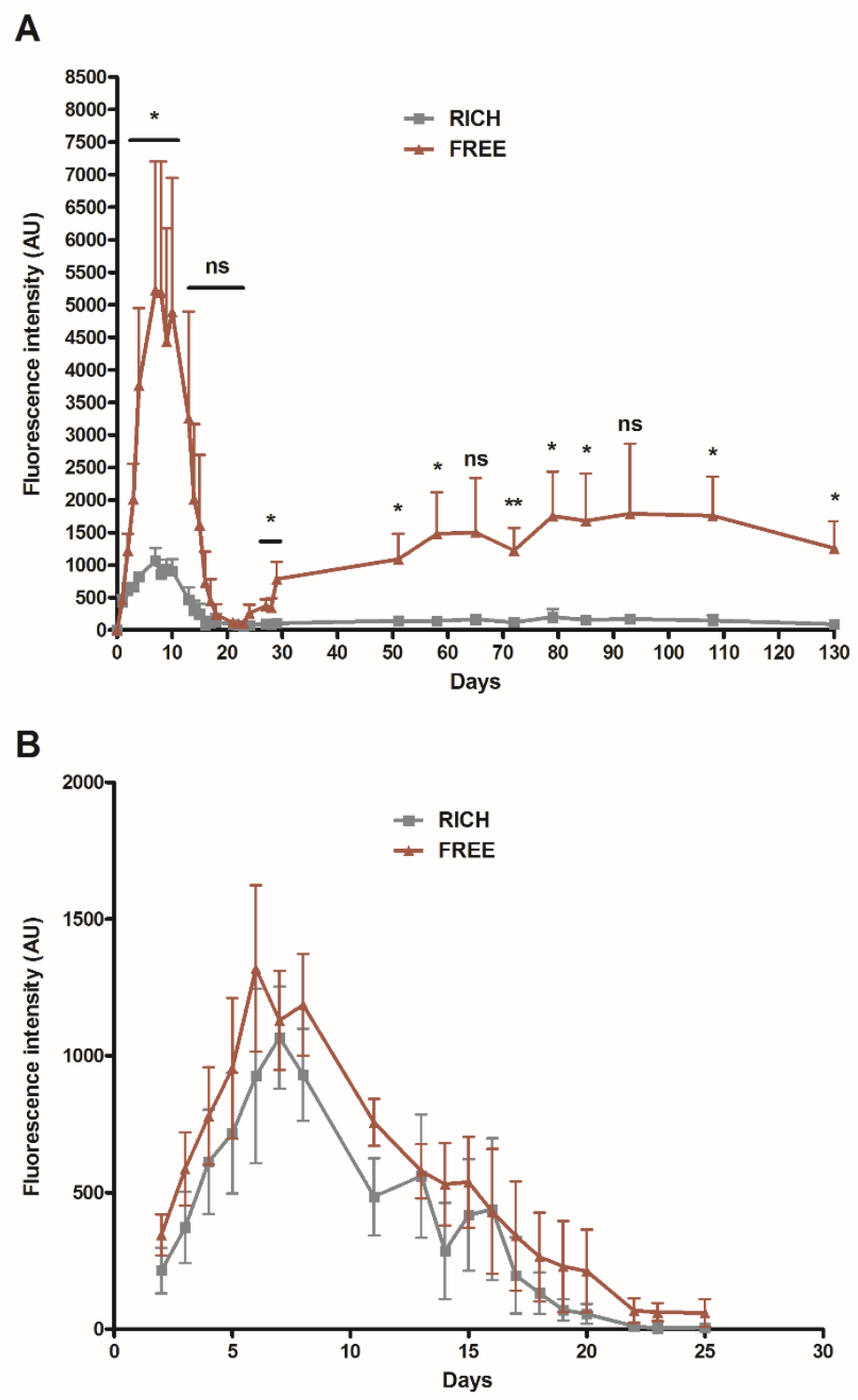

Figure 3: Mean fluorescence emission time course after GET of CPG-rich and CpG-free tdTomato and GFP plasmids.

$25 \mu \mathrm{g}$ of $\mathrm{CpG}$-rich or CpG-free plasmid DNA coding the fluorescent protein tdTomato (A) or GFP (B) were intradermally injected in the back of anesthetized C57BI/6 mice and the electrotransfer was performed with contact electrodes using the HV-MV parameters ( 4 trains : $100 \mu \mathrm{s}, 400 \mathrm{~V}+20 \mathrm{~ms}, 100 \mathrm{~V}$ ). tdTomato (A) and GFP (B) expression were followed over time by non-invasive fluorescence microscopy. Values are means \pm s.e.m. (A) for dtTomato, $n=2$ independent experiments with a total of 13 mice: 13 sites for cpGfree and 12 for $c p$ Grich. $P^{*}<0.05,{ }^{*} P<0.01$, ns=not significant (Two-way ANOVA analysis, one tailed post $t$-tests). (B) for GFP, $n=2$ independent experiments with a total of 6 mice: 6 sites for $c p G$ free and 6 for $c p$ Grich.

\section{Influence of the reporter gene}

We compared the level and the duration of plasmid expression after GET of different constructs differing by the encoded protein. C57BI/6 mice were injected intra-dermally with plasmid coding for 
either the GFP or the tdTomato proteins and were treated with 4 unipolar trains of HV-MV pulses using contact electrodes as described before. Expression was followed over time by non-invasive fluorescence microscopy. Again, no damage to the skin in the pulsed area was observed. No critical symptom was observed after GET. The expression of both proteins was detected at the same time.

A

D4

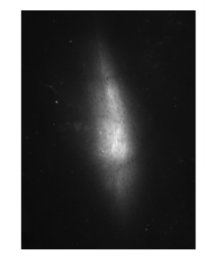

B

D8

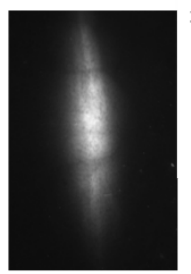

C

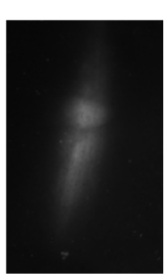

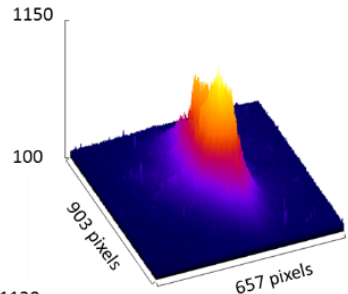
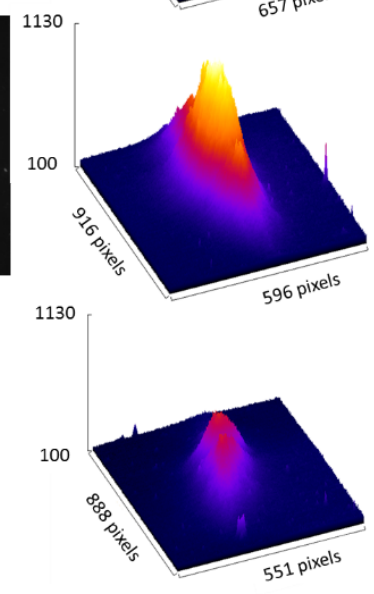
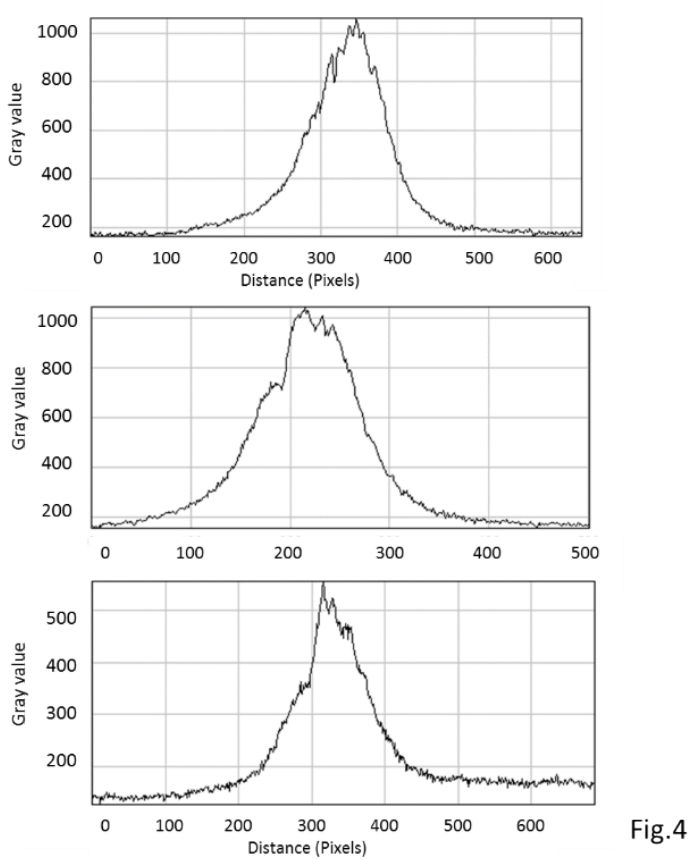

Fig.4 Image analysis of the GFP expression along the early part of the experiment

$25 \mu \mathrm{g}$ of $c p G$ free plasmid DNA coding the fluorescent protein GFP were intradermally injected in the back of anesthetized C57BI/ 6 mice and the electrotransfer was performed with contact electrodes using the HV-MV parameters ( 4 trains : $100 \mu \mathrm{s}, 400 \mathrm{~V}+20 \mathrm{~ms}, 100 \mathrm{~V}$ ). GFP expression was followed over time by non-invasive fluorescence microscopy. 100 pixels are $1.5 \mathrm{~mm}$.

A D4 Fluorescence image (700x750 pixels), surface plot, line plot

B D8 Fluorescence image (700x900 pixels), surface plot, line plot

C D18 Fluorescence image (500x500 pixels), surface plot, line plot

The pattern of the expression in the skin after GFP GET had some similarities with what was just reported for tdTomato GET (Fig. 2 and 4). Expression was detected as an elongated fluorescent spot. This was expected from the field distribution associated to the contact electrodes. No highly fluorescent stripe was observed and the width (obtained from the line plot analysis) was narrower. Levels of expression between the two plasmids could not be compared as the settings were different due to the difference in the spectra.

However, the enhancing effect of the deletion of the $\mathrm{CpG}$ sequence on the mean fluorescence intensity of the GFP protein was detected but at a low level (Fig.3B). The increase in emission was slower for 
GFP but a dramatic drop just followed (not statistically significant due to the scattering of the data between the different animals with GFP expression). Moreover, GFP expression was lost in all mice after 30 days. The biphasic signal of expression was not detected with the GFP coding plasmids (CpGrich as well as CpG-free).

\section{Reporter gene expression was detected on a long period in animals}

After more than 125 days (when we stopped the observations), tdTomato expression induced by CpGfree plasmids was detected in $85 \%$ of the mice while only $40 \%$ of the mice injected with a CpG-rich construct retained a low level tdTomato expression (Fig. 5B). The presence or not of $\mathrm{CpG}$ sequences in the GFP plasmid did not modify significantly the length of expression that was detected only for 32 days versus 28 days (fig $5 \mathrm{~A}$ ).

A

B
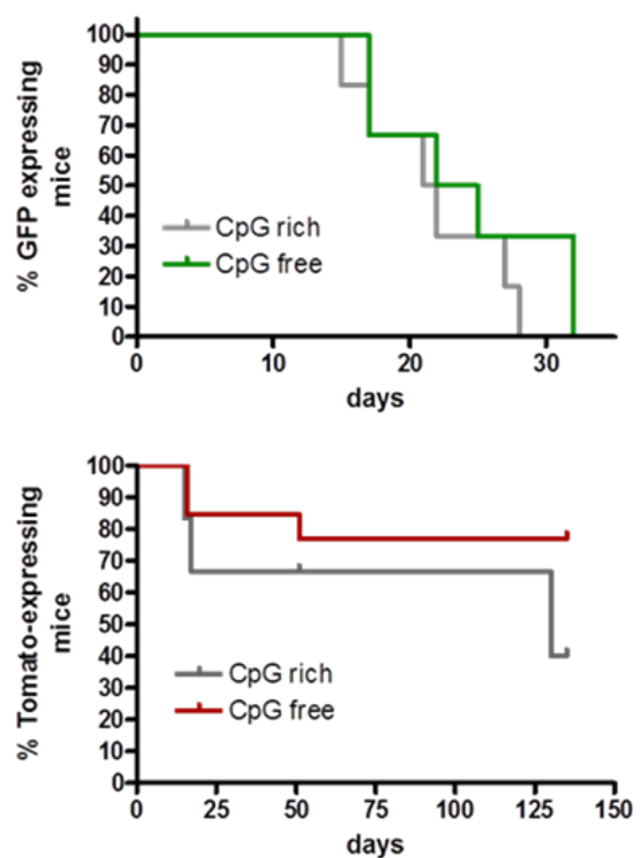

Fig.5. Percentage of mice expressing plasmid after GET with the different constructs.

$25 \mu \mathrm{g}$ of $\mathrm{CpG}$ rich or $\mathrm{CpG}$ free plasmid DNA coding the fluorescent protein GFP (A) or tdTomato (B) were intradermally injected in the back of anesthetized C57BI/6 mice and the electrotransfer was performed with contact electrodes ( 4 trains of HV-MV pulses $(100 \mu \mathrm{s}, 400 \mathrm{~V}+20 \mathrm{~ms}, 100 \mathrm{~V})$ ). The fluorescence was detected by imaging. $n=6$ mice for GFP and 13 for Tomato.

\section{Discussion}

tdTomato expression was observed to be long lived. The pattern of expression was heterogeneous suggesting that different layers of the skin were affected. The elongated stripes could be associated with the subdermal muscle fibers [2] [23]. Expression in muscle cells seemed present as long stripes of expression were observed on a long duration. A biophysical explanation was that the field distribution is heterogeneous [29] and a deeper penetration of field values supporting transfection was present in the volume in the middle of the electrode gap. The pulse settings with a long duration were reported to support expression in the deeper layers of the skin [2]. The conclusion was that the contact wire 
electrode device that we used was associated with a field distribution where the local field was high enough all across the skin to mediate gene transfer [33]. The image analysis showed that the area where expression was present (surface plot and line plot data) was controlling the mean fluorescence. The maximum in emission was less affected upon time meaning that expression remained high but more localized on long periods after the GET. This might be a result of the turnover of the skin cells. Keratinocytes had a limited life before forming the stratum corneum. Cells in the dermis, the collagen layer, the fat layer and the muscles remained alive on a longer time [1].

Protein expression obtained after GET was dependent on the construct as recently shown with nanoparticles mediated transfer. The size of the plasmid was proven a key element. Mini-circle plasmids were shown to induce a higher protein expression [34]. The size effect was described as a consequence of the damages associated with the transmembrane translocation of the construct [35]. The choice of the promotor played a role in the level of expression and its tissue specificity [36].

The CpG content of plasmids was playing a complex role in encoded protein expression in vitro [13, 14]. The risk associated with CpG dinucleotides in causing mutations [37] and gene silencing [38] led to the deletion of CpGs in the design of expression vectors for gene therapy [15, 16]. In this study, we observed that higher levels of reporter gene expression induced by GET were obtained with the CpGfree constructs (figure 3). This is coherent with previous studies using CpG-free constructs combined with other methods of gene transfer [12-14]. For GET, the size of the construct was one potential reason in the effect. $\mathrm{CpG}$-free plasmids were smaller than the $\mathrm{CpG}$-rich plasmids (S1). The $10 \%$ decrease in size could affect the transfection. Nevertheless, this was not observed with the GFP constructs that were smaller than the tomato ones. This supported the conclusion of Sato et al [7] that short immunostimulatory DNA sequences that contained $\mathrm{CpG}$ dinucleotides were necessary for gene vaccination, but down-regulated gene expression and thus might interfere with gene replacement therapy.

GFP expression was not easily detected by fluorescence imaging as the emission was not in the "optical window" [39, 40]. It could be detected only in the superficial layers of the skin (with a limited lifetime). This conclusion was supported by the observation of a smaller area of detected expression (narrower width shown by line plots) and the absence of stripes of high expression. This could explain why no effect of the $\mathrm{CpG}$ content could be detected on its expression and why the lifetime of the detection of expression was short (less than 30 days).

\section{Conclusion}

GET mediated expression in the skin is controlled by the CpG content of the transfected plasmid. Expression on the long term (more than 100 days) is obtained on $85 \%$ of the treated mice with CpG free construct associated to a proper design of the electrodes where a field distribution mediating gene transfer is present deep in the skin.

\section{Acknowledgements:}

Supported by grants of the Region Midi-Pyrénées (recherche en transfert clinique, normalisation, et innovation interdisciplinaire en biosanté $n^{\circ} 11052700$ et $n^{\circ} 13050740$ ) and of the EU FP7 Oncomirs (Grant 201102). Research was conducted in the scope of the EBAM European Associated Laboratory (LEA) and resulted from the networking efforts of the COST Action TD1104. (http://www.electroporation.net). We thank the "Toulouse Réseau Imagerie and Anexplo" core IPBS facilities (Genotoul, Toulouse, France). 


\section{Author Contributions}

EB and SC participated to the design of the project, performed the experiments on imaging, analyzed experimental data and wrote the draft. JPR designed and provided plasmids. GT read the final versions and provided valuable comments on the work. JT and MG designed the project, supervised all experiments, participated in the analysis of results and wrote the final version. All authors reviewed the manuscript.

\section{Competing interests}

The authors declare no competing interests. JPR and GT were employees at Invivogen.

[1] R.A.J.E. J.A. McGrath, F.M. Pope, Chapter 3 Anatomy and Organization of Human Skin, in: T. Burns, Breathnach, S., Cox, N., Griffiths, C. (Ed.) Rook's Textbook of Dermatology, Blackwell publishing, Malden USA, 2004.

[2] S. Kos, T. Blagus, M. Cemazar, U. Lampreht Tratar, M. Stimac, L. Prosen, T. Dolinsek, U. Kamensek, S. Kranjc, L. Steinstraesser, G. Vandermeulen, V. Preat, G. Sersa, Electrotransfer parameters as a tool for controlled and targeted gene expression in skin, Mol Ther Nucleic Acids, 5 (2016) e356.

[3] A. Gothelf, J. Gehl, Gene electrotransfer to skin; review of existing literature and clinical perspectives, Curr Gene Ther, 10 (2010) 287-299.

[4] A.K. Roos, F. Eriksson, J.A. Timmons, J. Gerhardt, U. Nyman, L. Gudmundsdotter, A. Brave, B. Wahren, P. Pisa, Skin electroporation: effects on transgene expression, DNA persistence and local tissue environment, PLoS One, 4 (2009) e7226.

[5] G. Vandermeulen, H. Richiardi, V. Escriou, J. Ni, P. Fournier, V. Schirrmacher, D. Scherman, V. Preat, Skin-specific promoters for genetic immunisation by DNA electroporation, Vaccine, 27 (2009) 42724277.

[6] K. Dayball, J. Millar, M. Miller, Y.H. Wan, J. Bramson, Electroporation enables plasmid vaccines to elicit CD8+ T cell responses in the absence of CD4+ T cells, J Immunol, 171 (2003) 3379-3384.

[7] Y. Sato, M. Roman, H. Tighe, D. Lee, M. Corr, M.D. Nguyen, G.J. Silverman, M. Lotz, D.A. Carson, E. Raz, Immunostimulatory DNA sequences necessary for effective intradermal gene immunization, Science, 273 (1996) 352-354.

[8] P. Matzinger, The danger model: a renewed sense of self, Science, 296 (2002) 301-305.

[9] A.M. Krieg, The role of CpG motifs in innate immunity, Curr Opin Immunol, 12 (2000) 35-43.

[10] H. Hemmi, O. Takeuchi, T. Kawai, T. Kaisho, S. Sato, H. Sanjo, M. Matsumoto, K. Hoshino, H. Wagner, K. Takeda, S. Akira, A Toll-like receptor recognizes bacterial DNA, Nature, 408 (2000) 740-745.

[11] C.J. Mann, X.M. Anguela, J. Montane, M. Obach, C. Roca, A. Ruzo, P. Otaegui, L.M. Mir, F. Bosch, Molecular signature of the immune and tissue response to non-coding plasmid DNA in skeletal muscle after electrotransfer, Gene Ther, 19 (2012) 1177-1186.

[12] M.F. Lindberg, T. Le Gall, N. Carmoy, M. Berchel, S.C. Hyde, D.R. Gill, P.A. Jaffres, P. Lehn, T. Montier, Efficient in vivo transfection and safety profile of a CpG-free and codon optimized luciferase plasmid using a cationic lipophosphoramidate in a multiple intravenous administration procedure, Biomaterials, 59 (2015) 1-11.

[13] A.P. Bauer, D. Leikam, S. Krinner, F. Notka, C. Ludwig, G. Langst, R. Wagner, The impact of intragenic CpG content on gene expression, Nucleic Acids Res, 38 (2010) 3891-3908.

[14] S. Krinner, A. Heitzer, B. Asbach, R. Wagner, Interplay of Promoter Usage and Intragenic CpG Content: Impact on GFP Reporter Gene Expression, Hum Gene Ther, 26 (2015) 826-840.

[15] N.S. Yew, H. Zhao, M. Przybylska, I.H. Wu, J.D. Tousignant, R.K. Scheule, S.H. Cheng, CpG-depleted plasmid DNA vectors with enhanced safety and long-term gene expression in vivo, Mol Ther, 5 (2002) 731-738. 
[16] N.S. Yew, S.H. Cheng, Reducing the immunostimulatory activity of CpG-containing plasmid DNA vectors for non-viral gene therapy, Expert Opin Drug Deliv, 1 (2004) 115-125.

[17] L. Steinstraesser, M.C. Lam, F. Jacobsen, P.E. Porporato, K.K. Chereddy, M. Becerikli, I. Stricker, R.E. Hancock, M. Lehnhardt, P. Sonveaux, V. Preat, G. Vandermeulen, Skin electroporation of a plasmid encoding hCAP-18/LL-37 host defense peptide promotes wound healing, Mol Ther, 22 (2014) 734-742. [18] P.D. Fisher, C.J. Brambila, J.R. McCoy, W.B. Kiosses, J.M. Mendoza, J. Oh, B.S. Yung, K. Schultheis, T.R.F. Smith, K.E. Broderick, Adipose tissue: a new target for electroporation-enhanced DNA vaccines, Gene Ther, 24 (2017) 757-767.

[19] F. Martinon, K. Kaldma, R. Sikut, S. Culina, G. Romain, M. Tuomela, M. Adojaan, A. Mannik, U. Toots, T. Kivisild, J. Morin, P. Brochard, B. Delache, A. Tripiciano, F. Ensoli, I. Stanescu, R. Le Grand, M. Ustav, Persistent immune responses induced by a human immunodeficiency virus DNA vaccine delivered in association with electroporation in the skin of nonhuman primates, Hum Gene Ther, 20 (2009) 1291-1307.

[20] K.E. Broderick, X. Shen, J. Soderholm, F. Lin, J. McCoy, A.S. Khan, J. Yan, M.P. Morrow, A. Patel, G.P. Kobinger, S. Kemmerrer, D.B. Weiner, N.Y. Sardesai, Prototype development and preclinical immunogenicity analysis of a novel minimally invasive electroporation device, Gene Ther, 18 (2011) 258-265.

[21] S. Kos, K. Vanvarenberg, T. Dolinsek, M. Cemazar, J. Jelenc, V. Preat, G. Sersa, G. Vandermeulen, Gene electrotransfer into skin using noninvasive multi-electrode array for vaccination and wound healing, Bioelectrochemistry, 114 (2017) 33-41.

[22] S. Guo, A. Donate, G. Basu, C. Lundberg, L. Heller, R. Heller, Electro-gene transfer to skin using a noninvasive multielectrode array, J Control Release, 151 (2011) 256-262.

[23] D.H. Amante, T.R. Smith, J.M. Mendoza, K. Schultheis, J.R. McCoy, A.S. Khan, N.Y. Sardesai, K.E. Broderick, Skin Transfection Patterns and Expression Kinetics of Electroporation-Enhanced Plasmid Delivery Using the CELLECTRA-3P, a Portable Next-Generation Dermal Electroporation Device, Hum Gene Ther Methods, 26 (2015) 134-146.

[24] D.H. Amante, T.R. Smith, B.B. Kiosses, N.Y. Sardesai, L.M. Humeau, K.E. Broderick, Direct transfection of dendritic cells in the epidermis after plasmid delivery enhanced by surface electroporation, Hum Gene Ther Methods, 25 (2014) 315-316.

[25] T.R. Smith, K. Schultheis, W.B. Kiosses, D.H. Amante, J.M. Mendoza, J.C. Stone, J.R. McCoy, N.Y. Sardesai, K.E. Broderick, DNA vaccination strategy targets epidermal dendritic cells, initiating their migration and induction of a host immune response, Mol Ther Methods Clin Dev, 1 (2014) 14054.

[26] J.R. McCoy, J.M. Mendoza, K.W. Spik, C. Badger, A.F. Gomez, C.S. Schmaljohn, N.Y. Sardesai, K.E. Broderick, A multi-head intradermal electroporation device allows for tailored and increased dose DNA vaccine delivery to the skin, Hum Vaccin Immunother, 10 (2014) 3039-3047.

[27] D. Huang, D. Zhao, X. Wang, C. Li, T. Yang, L. Du, Z. Wei, Q. Cheng, H. Cao, Z. Liang, Y. Huang, Z. Li, Efficient delivery of nucleic acid molecules into skin by combined use of microneedle roller and flexible interdigitated electroporation array, Theranostics, 8 (2018) 2361-2376.

[28] L. Daugimont, N. Baron, G. Vandermeulen, N. Pavselj, D. Miklavcic, M.C. Jullien, G. Cabodevila, L.M. Mir, V. Preat, Hollow microneedle arrays for intradermal drug delivery and DNA electroporation, J Membr Biol, 236 (2010) 117-125.

[29] T.S. Kupper, R.C. Fuhlbrigge, Immune surveillance in the skin: mechanisms and clinical consequences, Nat Rev Immunol, 4 (2004) 211-222.

[30] S. Mazeres, D. Sel, M. Golzio, G. Pucihar, Y. Tamzali, D. Miklavcic, J. Teissie, Non invasive contact electrodes for in vivo localized cutaneous electropulsation and associated drug and nucleic acid delivery, J Control Release, 134 (2009) 125-131.

[31] S. Pedron-Mazoyer, J. Plouet, L. Hellaudais, J. Teissie, M. Golzio, New anti angiogenesis developments through electro-immunization: optimization by in vivo optical imaging of intradermal electro gene transfer, Biochim Biophys Acta, 1770 (2007) 137-142.

[32] L. Pasquet, S. Chabot, E. Bellard, B. Markelc, M.P. Rols, J.P. Reynes, G. Tiraby, F. Couillaud, J. Teissie, M. Golzio, Safe and efficient novel approach for non-invasive gene electrotransfer to skin, Sci Rep, 8 (2018) 16833. 
[33] D. Miklavcic, K. Beravs, D. Semrov, M. Cemazar, F. Demsar, G. Sersa, The importance of electric field distribution for effective in vivo electroporation of tissues, Biophys J, 74 (1998) 2152-2158.

[34] S. Chabot, J. Orio, M. Schmeer, M. Schleef, M. Golzio, J. Teissie, Minicircle DNA electrotransfer for efficient tissue-targeted gene delivery, Gene Ther, 20 (2013) 62-68.

[35] L.L. Lesueur, L.M. Mir, F.M. Andre, Overcoming the Specific Toxicity of Large Plasmids Electrotransfer in Primary Cells In Vitro, Mol Ther Nucleic Acids, 5 (2016) e291.

[36] S. Kos, N. Tesic, U. Kamensek, T. Blagus, M. Cemazar, S. Kranjc, J. Lavrencak, G. Sersa, Improved Specificity of Gene Electrotransfer to Skin Using pDNA Under the Control of Collagen Tissue-Specific Promoter, J Membr Biol, 248 (2015) 919-928.

[37] G.P. Pfeifer, Mutagenesis at methylated CpG sequences, Curr Top Microbiol Immunol, 301 (2006) 259-281.

[38] M. Hisano, H. Ohta, Y. Nishimune, M. Nozaki, Methylation of CpG dinucleotides in the open reading frame of a testicular germ cell-specific intronless gene, Tact1/Actl7b, represses its expression in somatic cells, Nucleic Acids Res, 31 (2003) 4797-4804.

[39] R. Weissleder, V. Ntziachristos, Shedding light onto live molecular targets, Nat Med, 9 (2003) 123128.

[40] M. Golzio, M.P. Rols, B. Gabriel, J. Teissie, Optical imaging of in vivo gene expression: a critical assessment of the methodology and associated technologies, Gene Ther, 11 Suppl 1 (2004) S85-91.

\section{Supplementary data}

S1

pCpGfree GFP:

Length : $3741 \mathrm{pb}$

Enhancer CMV murin CpG-free : 430 pb

Promotor EF1 humain CpG-free : 224 pb

pCpGrich GFP:[3]

Length : $4009 \mathrm{pb}$

Enhancer CMV murin wt (5 CpGs) : 561 pb

Promotor EF1 humain wt (16 CpGs) : 225 pb

pCpGfree tdTomato:

Length : $4451 \mathrm{pb}$

Enhancer CMV murin CpG-free : 430 pb

Promotor EF1 humain CpG-free : 224 pb

pCpGrich tdTomato:

Length : $4719 \mathrm{pb}$ 
Enhancer CMV murin wt (5 CpGs) : $561 \mathrm{pb}$

Promotor EF1 humain wt (16 CpGs) : 225 pb 
Legends

Fig. 1 High Voltage (HV) consists in $100 \mu$ square waved pulses of $400 \mathrm{~V}$ and Medium Voltage (MV) were $20 \mathrm{~ms}$ square waved pulses of $100 \mathrm{~V}$. The intermediate time delay was $50 \mathrm{~ms}$. The frequency was $1 \mathrm{~Hz}$.

Fig.2 Image analysis of the dTomato expression along the early part of the experiment

$25 \mu \mathrm{g}$ of CpG-free plasmid DNA coding the fluorescent protein tdTomato were intradermally injected in the back of anesthetized $\mathrm{C} 57 \mathrm{BI} / 6$ mice and the electrotransfer was performed with contact electrodes using the HV-MV parameters ( 4 trains : $100 \mu \mathrm{s}, 400 \mathrm{~V}+20 \mathrm{~ms}, 100 \mathrm{~V}$ ). tdTomato expression was followed over time by non-invasive fluorescence microscopy. 100 pixels are $1.5 \mathrm{~mm}$.

A D4 Fluorescence image (700x750 pixels), surface plot, line plot

B D8 Fluorescence image (700x900 pixels), surface plot, line plot

C D18 Fluorescence image (500x500 pixels), surface plot, line plot

Figure 3: Mean fluorescence emission time course after GET of CpG-rich and CpG-free tdTomato and GFP plasmids.

$25 \mu \mathrm{g}$ of $\mathrm{CpG}$-rich or CpG-free plasmid DNA coding the fluorescent protein tdTomato or GFP were intradermally injected in the back of anesthetized C57BI/6 mice and the electrotransfer was performed with contact electrodes using the HV-MV parameters ( 4 trains : $100 \mu \mathrm{s}, 400 \mathrm{~V}+20 \mathrm{~ms}, 100 \mathrm{~V}$ ). tdTomato (A) and GFP (B) expression were followed over time by non-invasive fluorescence microscopy. Values are means \pm s.e.m. (A) $n=2$ independent experiments with a total of 13 mice: 13 sites for cpGfree and 12 for $\mathrm{cpGrich} . \mathrm{P}^{*}<0.05,{ }^{*} \mathrm{P}<0.01$, ns=not significant (Two-way ANOVA analysis, one tailed post t-tests). (B) $n=2$ independent experiments with a total of 6 mice for GFP: 6 sites for cpGfree and 6 for cpGrich.

Fig.4 Image analysis of the GFP expression along the early part of the experiment

$25 \mu \mathrm{g}$ of $\mathrm{cpG}$ free plasmid DNA coding the fluorescent protein GFP were intradermally injected in the back of anesthetized $\mathrm{C} 57 \mathrm{BI} / 6$ mice and the electrotransfer was performed with contact electrodes using the HV-MV parameters ( 4 trains : $100 \mu \mathrm{s}, 400 \mathrm{~V}+20 \mathrm{~ms}, 100 \mathrm{~V}$ ). GFP expression was followed over time by non-invasive fluorescence microscopy. 100 pixels are $1.5 \mathrm{~mm}$.

A D4 Fluorescence image (700x750 pixels), surface plot, line plot

B D8 Fluorescence image (700x900 pixels), surface plot, line plot

C D18 Fluorescence image (500x500 pixels), surface plot, line plot

Fig.5. Percentage of mice expressing plasmid after GET with the different constructs.

$25 \mu \mathrm{g}$ of $\mathrm{CpG}$ rich or $\mathrm{CpG}$ free plasmid DNA coding the fluorescent protein GFP (A) or tdTomato (B) were intradermally injected in the back of anesthetized C57BI/6 mice and the electrotransfer was 
performed with contact electrodes ( 4 trains of HV-MV pulses $(100 \mu \mathrm{s}, 400 \mathrm{~V}+20 \mathrm{~ms}, 100 \mathrm{~V})$ ). The fluorescence was detected by imaging. $n=6$ mice for GFP and 13 for Tomato. . 


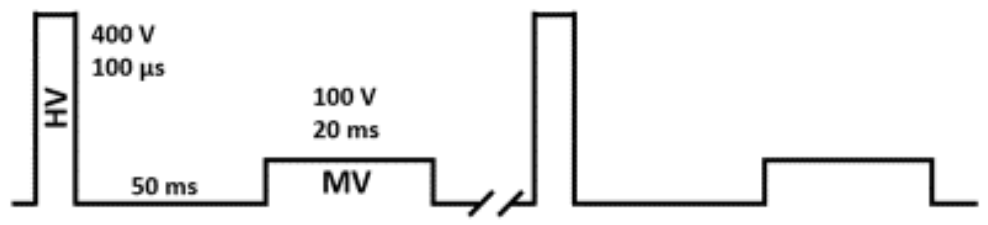

Fig.1 
A

D4

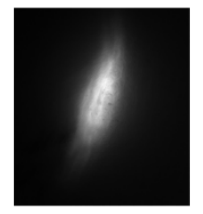

B

D8

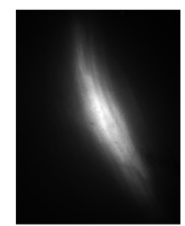

C

D18

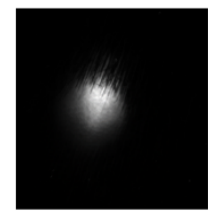

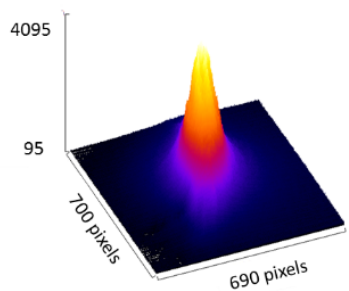
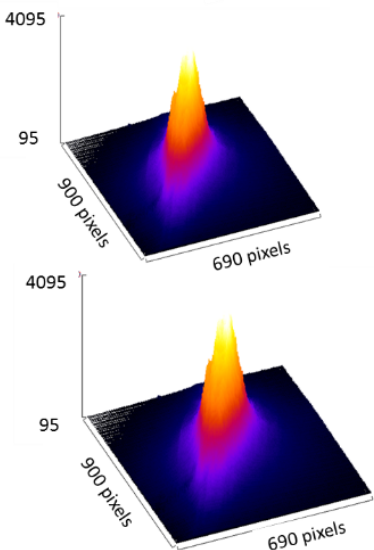
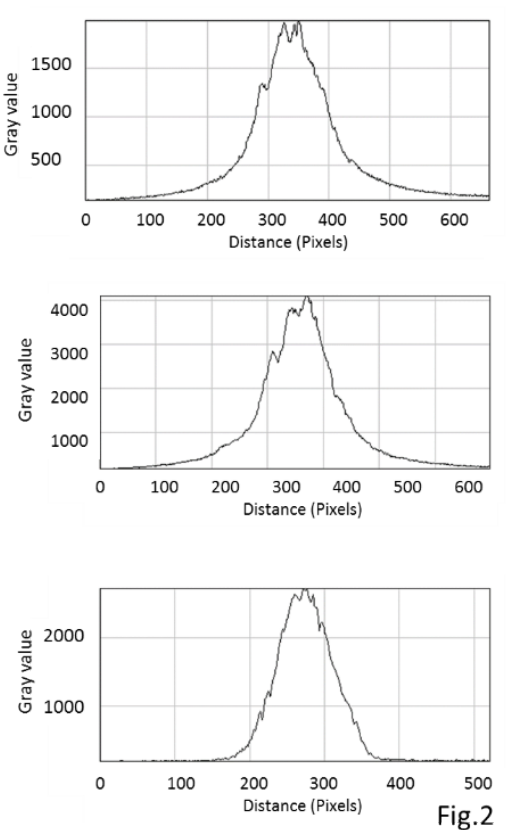

Fig.2 

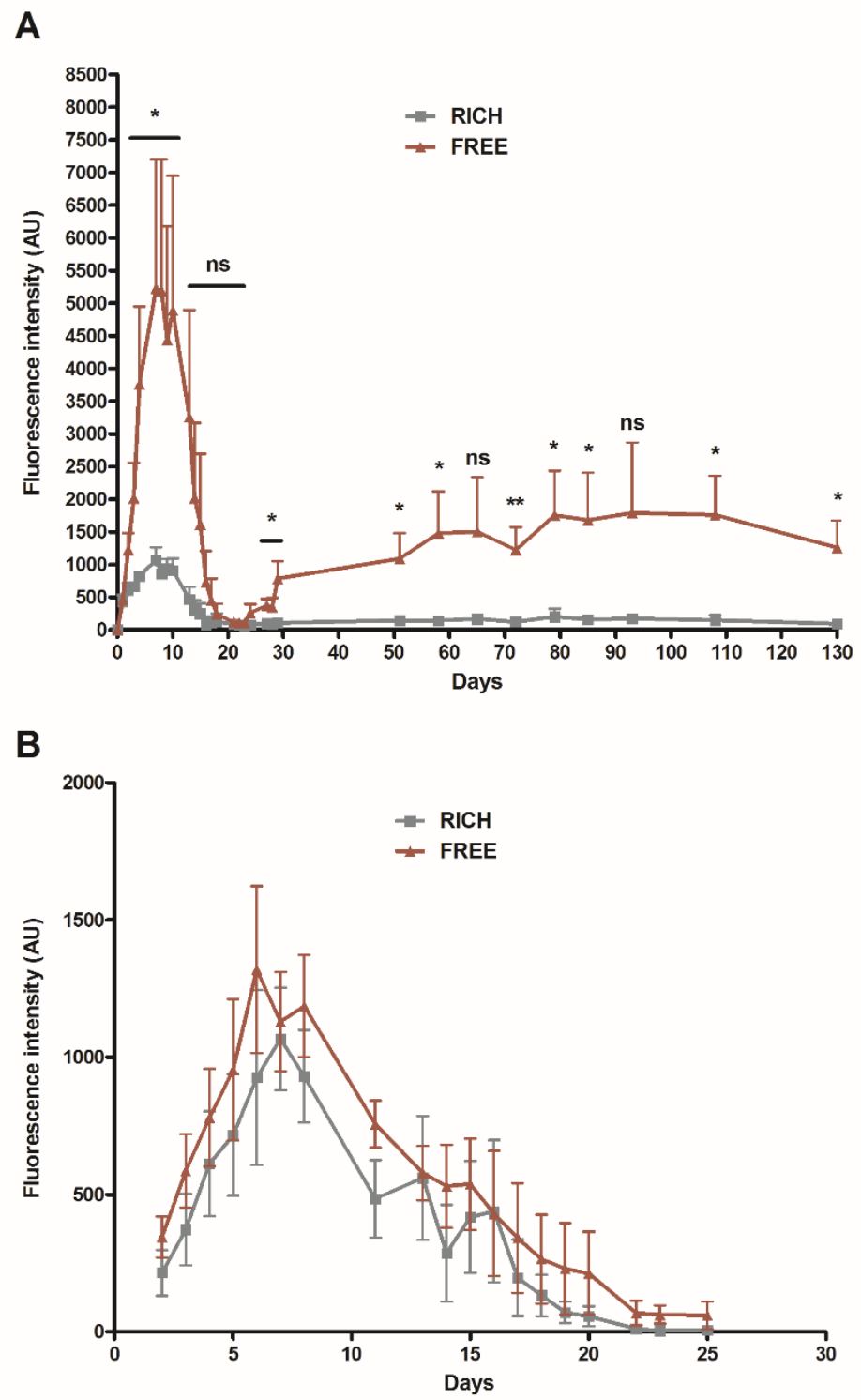

Fig. 3 
A

D4

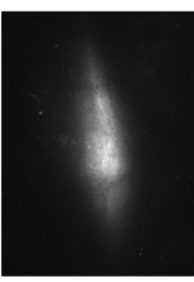

B
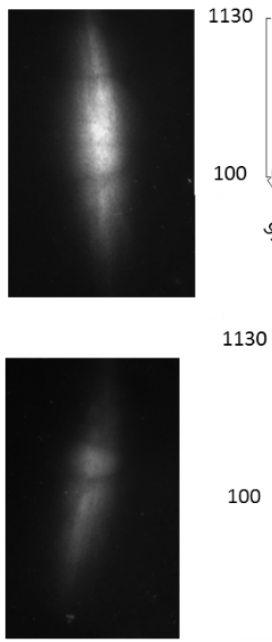

1130

C
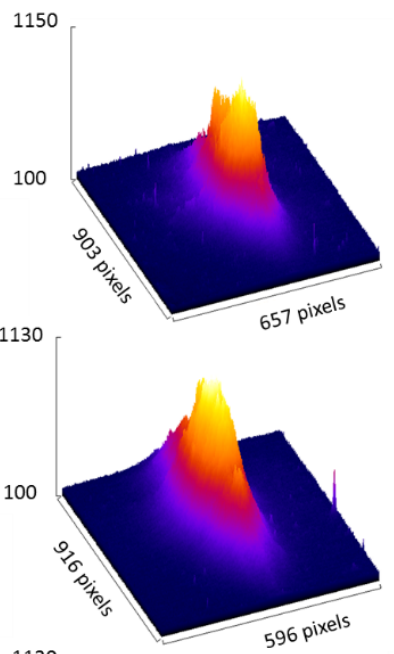

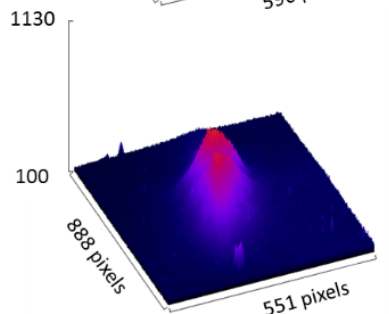

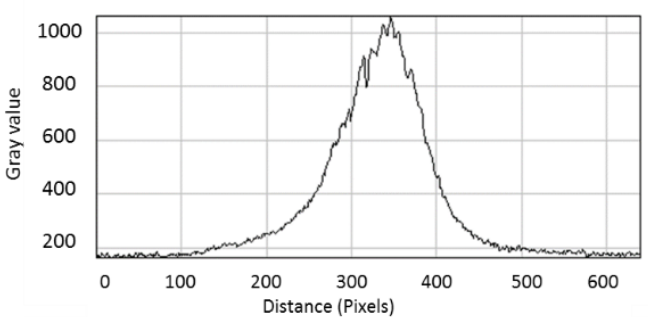
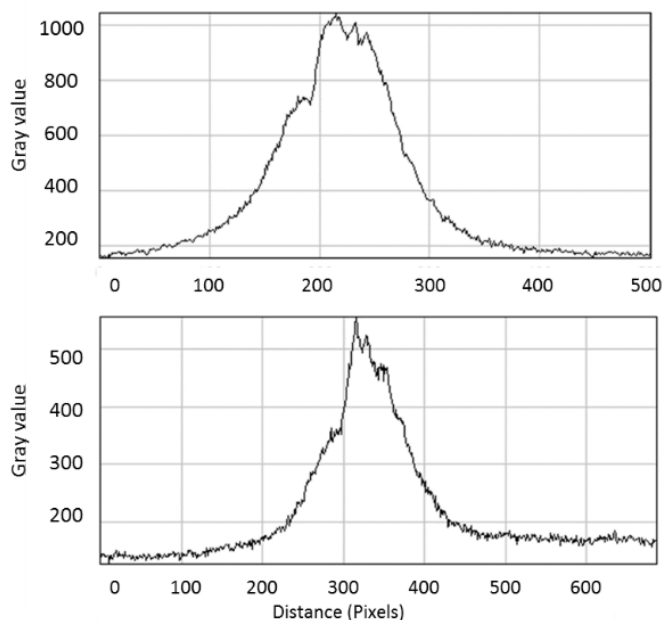

Fig.4

Fig.4 

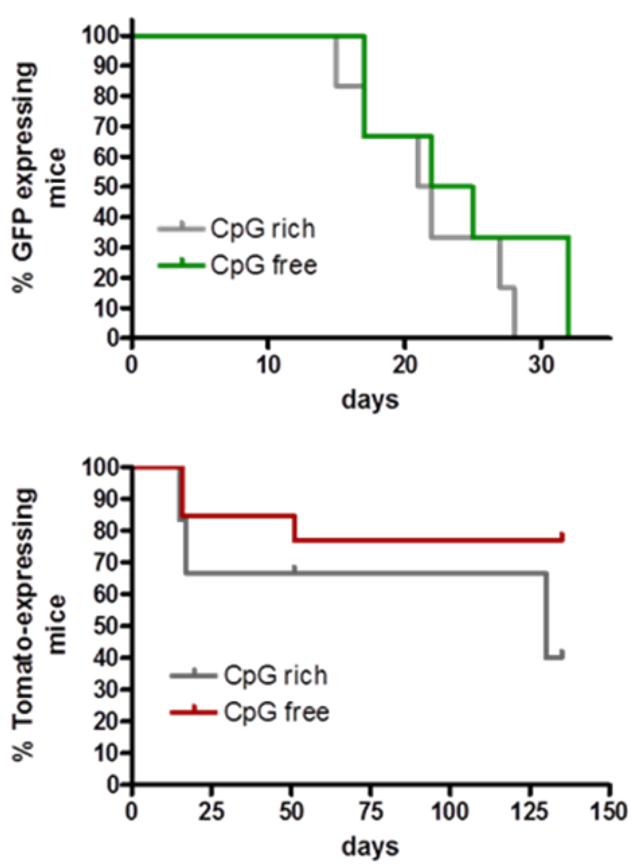

Fig.5 


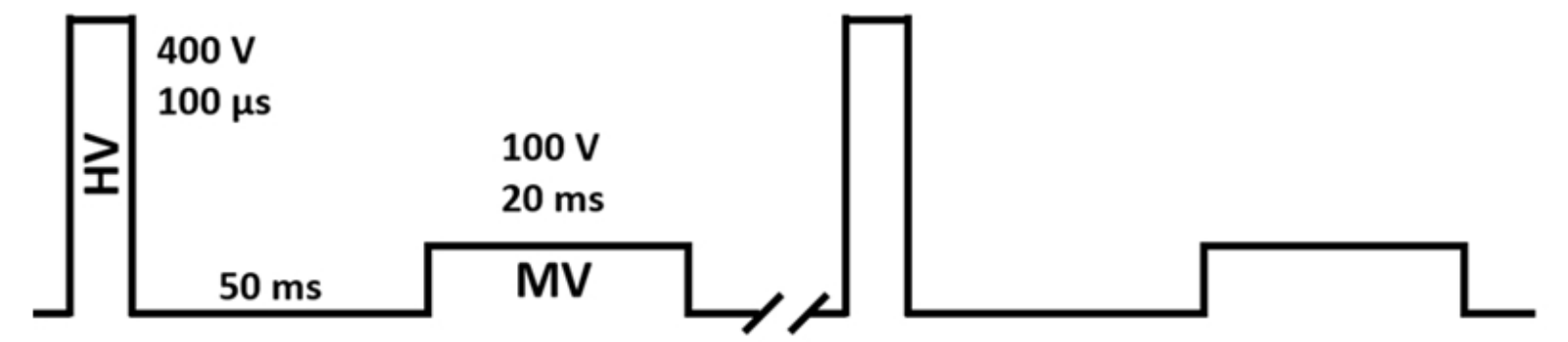

Fig.1 
A

D4

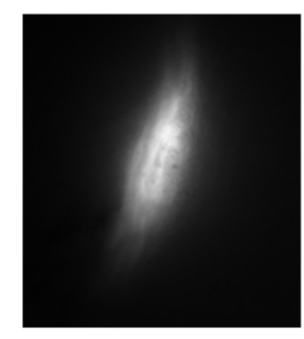

D8

C

D18

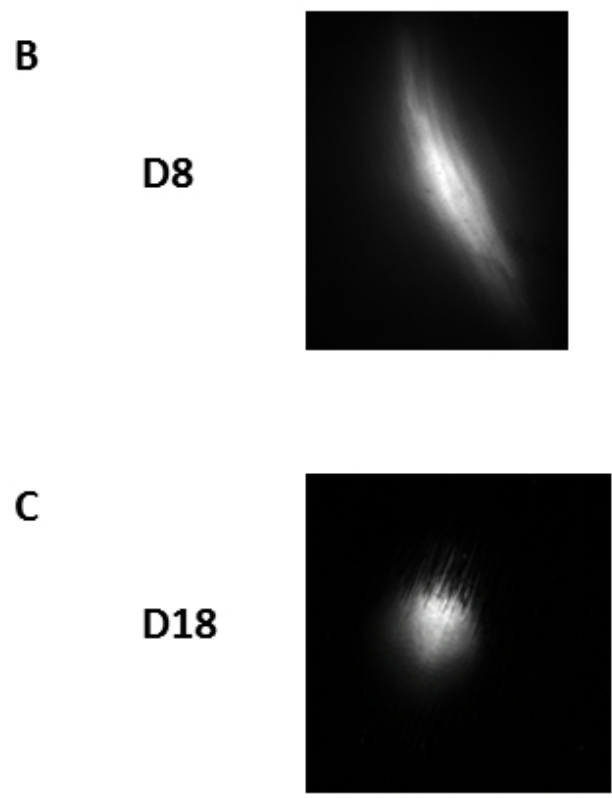

4095

B
95
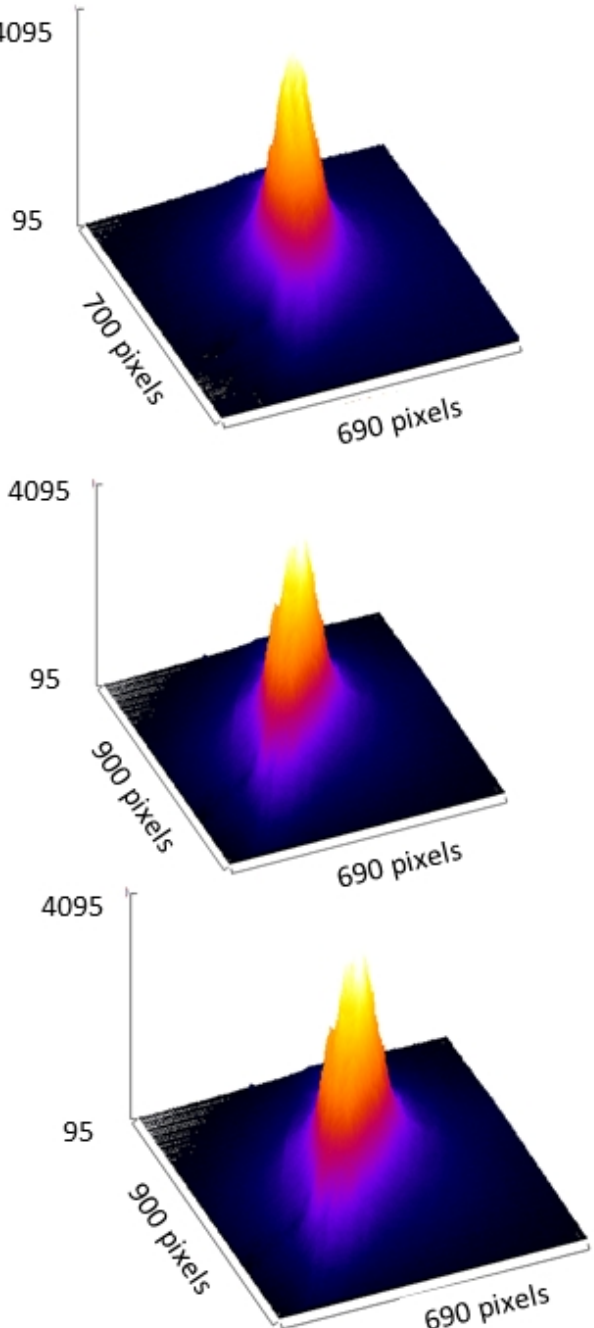
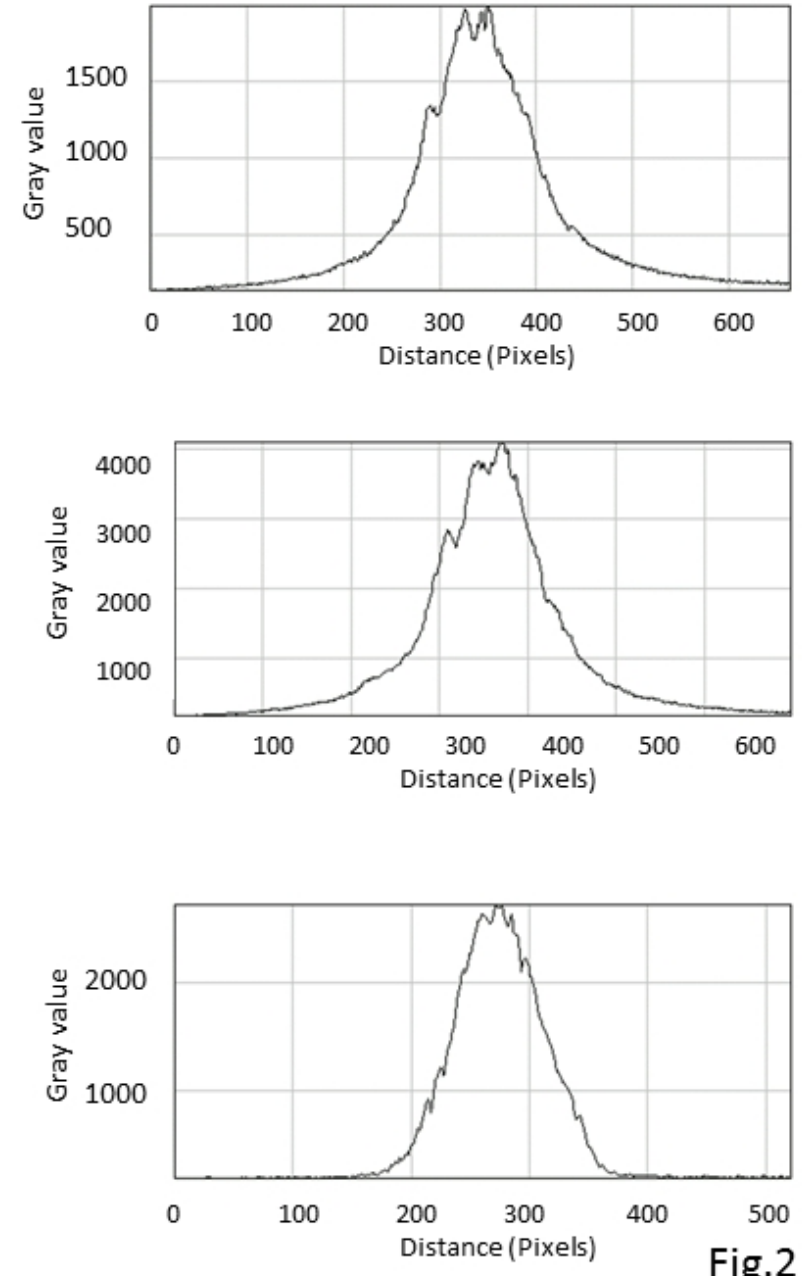
A

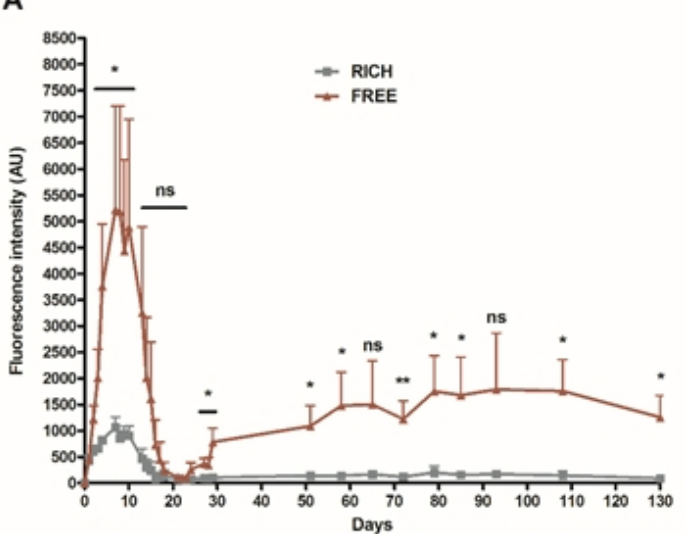

B

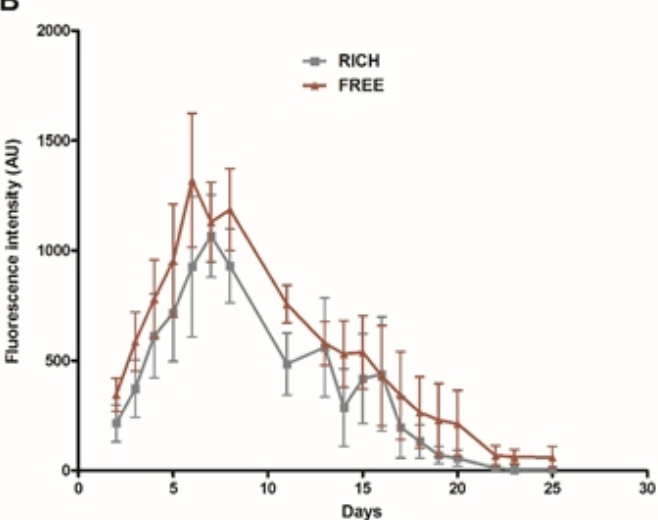

Fig.3 
A

D4

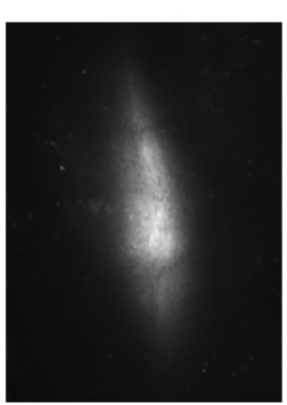

B

D8

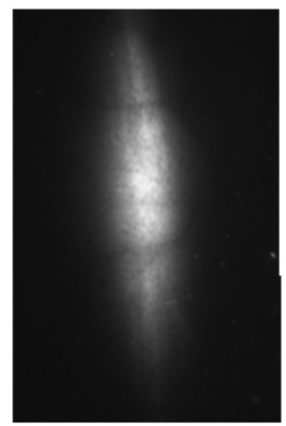

C

D18
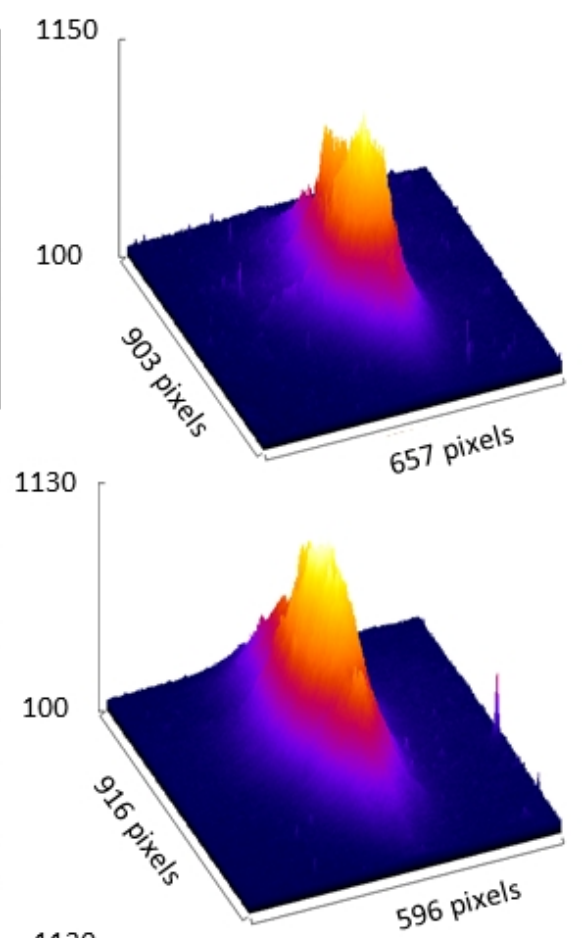

100

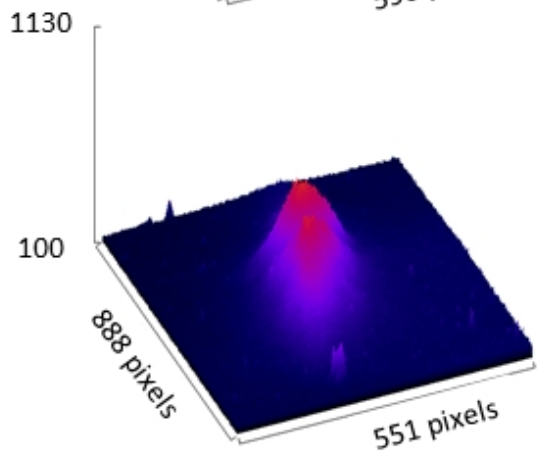

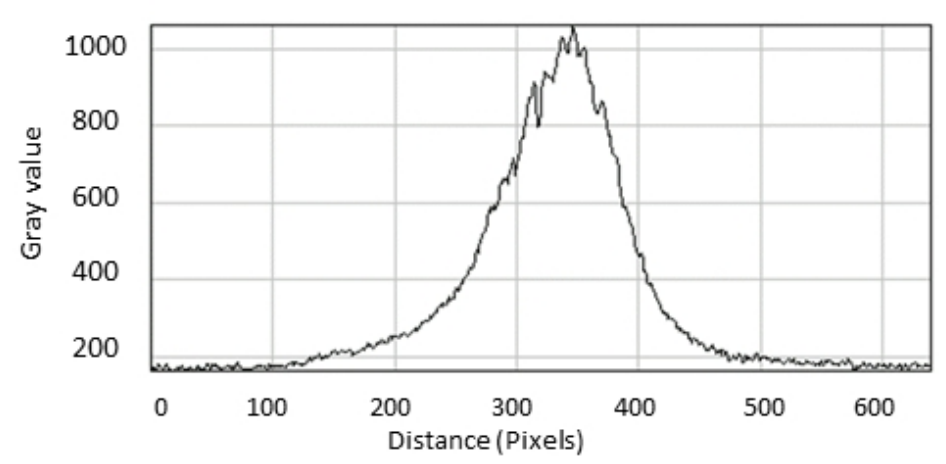
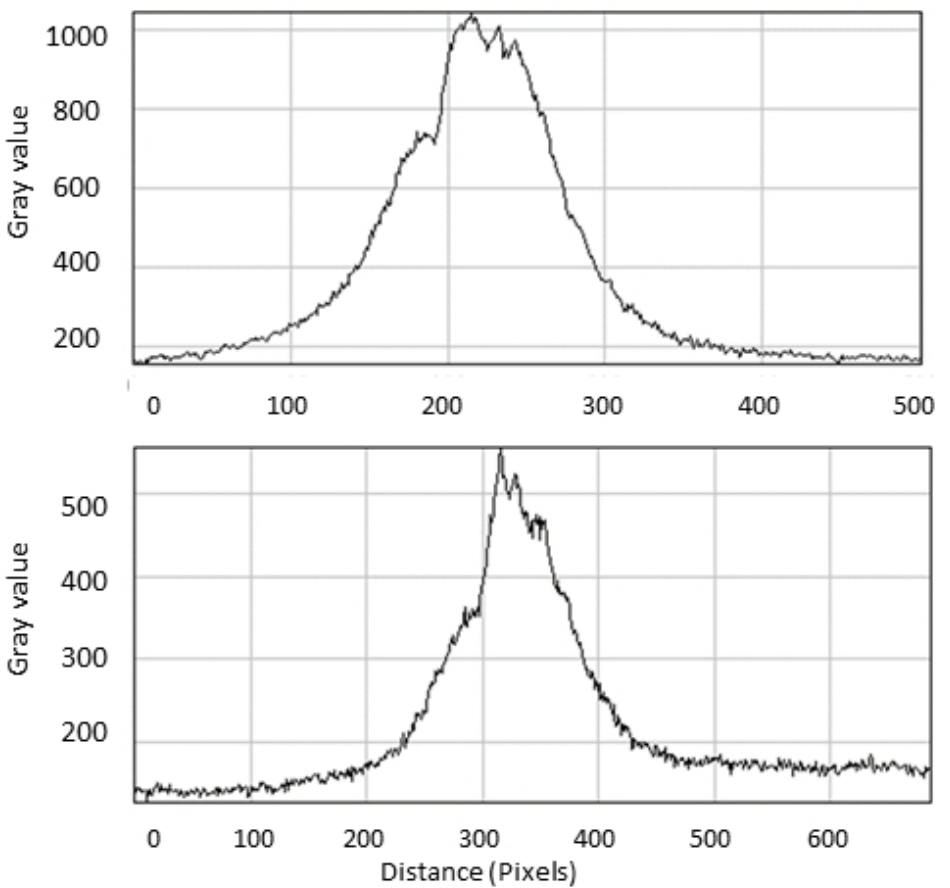

Fig.4 

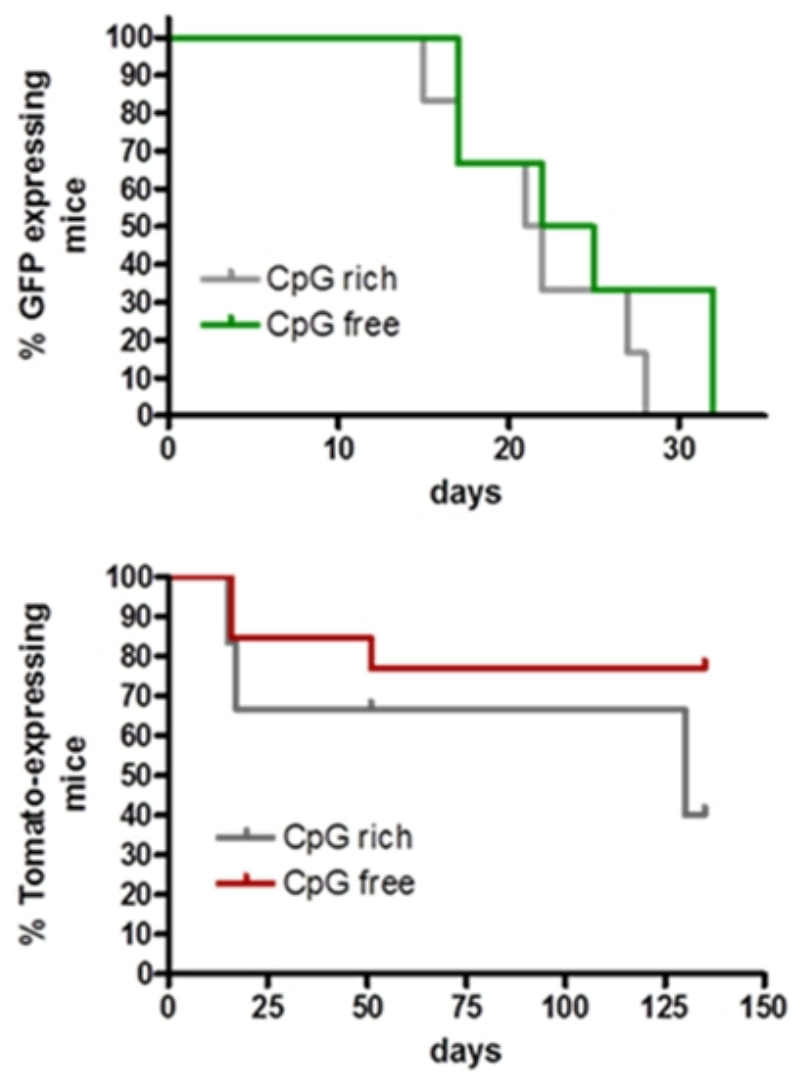


\section{Supplementary data}

S1

pCpGfree GFP:

Length : $3741 \mathrm{pb}$

Enhancer CMV murin CpG-free : 430 pb

Promotor EF1 humain CpG-free : 224 pb

pCpGrich GFP:[3]

Length : $4009 \mathrm{pb}$

Enhancer CMV murin wt (5 CpGs) : 561 pb

Promotor EF1 humain wt (16 CpGs) : 225 pb

pCpGfree tdTomato:

Length : $4451 \mathrm{pb}$

Enhancer CMV murin CpG-free : 430 pb

Promotor EF1 humain CpG-free : 224 pb

pCpGrich tdTomato:

Length : $4719 \mathrm{pb}$

Enhancer CMV murin wt (5 CpGs) : 561 pb

Promotor EF1 humain wt (16 CpGs) : 225 pb 